\author{
UNIVERSIDADE DE SÃO PAULO \\ ESCOLA DE ENFERMAGEM DE RIBEIRÃO PRETO
}

ANAÍSA BIANCHINI

Simulação clínica em comunicação na educação em enfermagem: estudo randomizado sobre a satisfação, confiança e auto percepção de estudantes

RIBEIRÃO PRETO 


\section{ANAÍSA BIANCHINI}

Simulação clínica em comunicação na educação em enfermagem: estudo randomizado sobre a satisfação, confiança e auto percepção de estudantes

Dissertação apresentada à Escola de Enfermagem de Ribeirão Preto da Universidade de São Paulo para obtenção do título de Mestre em Ciências.

Área de concentração: Formação de profissionais e de professores na área da saúde do Programa de PósGraduação em Enfermagem Fundamental.

Orientador: Prof. ${ }^{a}$ Dr. ${ }^{a}$ Fernanda dos Santos Nogueira de Góes

RIBEIRÃO PRETO 
Autorizo a reprodução e divulgação total ou parcial deste trabalho, por qualquer meio convencional ou eletrônico, para fins de estudo e pesquisa, desde que citada a fonte.

Bianchini, Anaísa

Simulação clínica em comunicação na educação em enfermagem: estudo randomizado sobre a satisfação, confiança e auto percepção de estudantes. Ribeirão Preto, 2019.

77 p. : il. ; $30 \mathrm{~cm}$

Dissertação de Mestrado, apresentada à Escola de Enfermagem de Ribeirão Preto/USP. Área de concentração: formação de profissionais e de professores na área da saúde.

Orientador: Góes, Fernanda dos Santos Nogueira de.

1. Educação em Enfermagem. 2. Comunicação. 3. Simulação. 
Nome: Anaísa Bianchini

Título: Simulação clínica em comunicação na educação em enfermagem: estudo randomizado sobre a satisfação, confiança e auto percepção de estudantes

Dissertação apresentada à Escola de Enfermagem de Ribeirão Preto da Universidade de São Paulo para obtenção do título de Mestre em Ciências na área de concentração: Formação de profissionais e professores na área da saúde.

Aprovado em:

Comissão Julgadora

Prof. Dr.(a)

Instituição:

Julgamento:

Profa. Dr.(a)

Instituição:

Julgamento:

Prof. Dr.(a)

Instituição:

Julgamento: 
Dedico esta dissertação a meus pais, à memória da minha avó e minha orientadora, com amor, admiração e gratidão por sua compreensão, auxílio e apoio ao longo do período de elaboração deste trabalho. Dedico também a você, leitor, esperando que possa auxiliar na construção do seu conhecimento. 
Agradeço à Deus, pela força que me deu e pelas oportunidades que pude viver para chegar até aqui.

Agradeço meus amados pais, Erica Perna Bianchini e João Anilson Bianchini, por toda a ajuda e amor que me proporcionaram, pela criação, educação e formação do meu caráter e de toda minha realização profissional até agora.

À Escola de Enfermagem de Ribeirão Preto da Universidade de São Paulo, pela oportunidade de cursar a graduação e pós-graduação nível mestrado.

À minha orientadora, que me abraçou e acolheu em um momento difícil e me ajudou a reerguer e construir essa dissertação.

Aos coordenadores de enfermagem Liliane Passarelli Rodrigues Silva e da educação em enfermagem Fábio Veiga Spolidorio das instituições participantes, por me permitir realizar as coletas de dados.

A meus amigos, enfermeiros, que caminharam ao meu lado, na graduação e pós-graduação e que jamais esquecerei o que a pós-graduação me ensinou e os presentes que essa vida me trouxe. 
BIANCHINI, Anaísa. Simulação clínica em comunicação na educação em enfermagem: estudo randomizado sobre a satisfação, confiança e auto percepção de estudantes. 2019. Dissertação (Mestrado em Ciências) - Escola de Enfermagem de Ribeirão Preto, Universidade de São Paulo, Ribeirão Preto, 2019.

\section{RESUMO}

Introdução: O cenário da enfermagem brasileira conta predominantemente com as categorias de técnicos de enfermagem e auxiliares de enfermagem. Levando em consideração sua importância no cuidado à saúde da pessoa, da família e da comunidade fundamentada em princípios humanos, éticos e do SUS, torna-se necessária a qualificação da atenção em saúde, a qual se origina desde a formação inicial do estudante. Dessa forma, a utilização de metodologias ativas no ensino pode favorecer a aprendizagem de estudantes da educação profissional em enfermagem; por isso vislumbramos a simulação clínica como uma estratégia de ensino que pode auxiliar na formação do aluno e colaborar no desenvolvimento de diversas habilidades cognitivas, procedimentais e atitudinais, entre elas a comunicação. Torna-se objetivo do estudo verificar se a simulação clínica em comunicação colabora com a formação do profissional de enfermagem. Método: estudo misto randomizado com a utilização de grupo controle e grupo intervenção com amostra de 37 participantes do módulo I (auxiliar de enfermagem) de uma escola técnica particular do interior do estado de São Paulo. Foram aplicados aos participantes instrumentos de preenchimento contendo dados sócio demográficos, o instrumento HCAT (Health Communication Assessment Tool) que avalia a comunicação em saúde e a Escala de Satisfação de Estudantes e Autoconfiança na Aprendizagem a fim de verificar quantitativamente a satisfação e o aprendizado do aluno utilizando a simulação clínica em comunicação. Posteriormente, foi realizada uma entrevista com os participantes selecionados a qual foi gravada para realização de análise qualitativa utilizando referencial teórico. Resultados: a análise quantitativa da escala de satisfação demonstrou que os estudantes se mostraram altamente confiantes e satisfeitos com sua aprendizagem, porém, o resultado da avaliação da habilidade de comunicação (HCAT) demonstrou que os alunos não estavam preparados para comunicar-se adequadamente. Ademais, as falas das entrevistas quando colocam a comunicação aplicada no contexto do cuidado tecnicista, repetitivo e apenas informacional reforçam os resultados evidenciados pela HCAT. Conclusões: Um único cenário de simulação clínica de alta fidelidade não demonstrou diferenças significativas entre os participantes do grupo controle versus grupo intervenção, o que demonstra que a estratégia deve obter maior valorização e capacitação 
docentes para a utilização da mesma e ser mais bem implementada em disciplinas e ao longo do curso técnico de enfermagem.

Palavras-chave: Educação em Enfermagem. Comunicação. Simulação. 
BIANCHINI, Anaísa. Clinical simulation in communication in nursing education: a randomized study on the satisfaction, confidence and self-perception of students. 2019. Dissertação (Mestrado em Ciências) - Escola de Enfermagem de Ribeirão Preto, Universidade de São Paulo, Ribeirão Preto, 2019.

\begin{abstract}
Introduction: The Brazilian nursing scene counts predominantly with the categories of nursing technicians and nursing assistants. Taking into consideration its importance in the health care of the person, family and community based on human, ethical and SUS principles, it becomes necessary to qualify health care, which originates from the initial formation of the student. Thus, the use of active methodologies in teaching can favor the learning of students of professional education in nursing; for this reason, we envisage clinical simulation as a teaching strategy that can aid in the formation of the student and collaborate in the development of several cognitive, procedural and attitudinal abilities, among them communication. It is the objective of the study to verify if the clinical simulation in communication collaborates with the training of the nursing professional. Method: randomized mixed study using the control group and intervention group with a sample of 37 participants of the module I (nursing assistant) of a private technical school in the interior of the state of São Paulo. Participants were applied to fill in instruments containing sociodemographic data, the HCAT (Health Communication Assessment Tool) that evaluates health communication and the Student Satisfaction Scale and Self-Confidence in Learning in order to quantitatively verify student's satisfaction and learning using clinical simulation in communication. Subsequently, an interview with the selected participants was carried out, which was recorded for a qualitative analysis using a theoretical reference. Results: The quantitative analysis of the satisfaction scale demonstrated that the students were highly confident and satisfied with their learning, but the results of the communication ability assessment (HCAT) showed that the students were not prepared to communicate adequately. In addition, the statements of interviews when they put the communication applied in the context of technical, repetitive and informational care reinforce the results evidenced by the HCAT. Conclusions: A single scenario of high fidelity clinical simulation did not show significant differences between participants in the control group versus intervention group, which demonstrates that the strategy must obtain greater appreciation and training of teachers to use it and be better implemented in disciplines and throughout the technical nursing course.
\end{abstract}

Key words: Nursing Education. Communication. Simulation. 
BIANCHINI, Anaísa. 2019. Simulación clínica en comunicación en educación de enfermería: un estudio aleatorio sobre la satisfacción, la confianza y la autopercepción de los estudiantes. Dissertação (Mestrado em Ciências) - Escola de Enfermagem de Ribeirão Preto, Universidade de São Paulo, Ribeirão Preto, 2019.

\section{RESUMEN}

Introducción: La escena de enfermería brasileña cuenta predominantemente con las categorías de técnicos de enfermería y auxiliares de enfermería. Teniendo en cuenta su importancia en el cuidado de la salud de la persona, la familia y la comunidad en base a los principios humanos, éticos y del SUS, se hace necesario calificar el cuidado de la salud, que se origina a partir de la formación inicial del estudiante. Por lo tanto, el uso de metodologías activas en la enseñanza puede favorecer el aprendizaje de los estudiantes de educación profesional en enfermería; Por este motivo, consideramos la simulación clínica como una estrategia de enseñanza que puede ayudar en la formación del estudiante y colaborar en el desarrollo de varias habilidades cognitivas, de procedimiento y de actitud, entre ellas la comunicación. El objetivo del estudio es verificar si la simulación clínica en comunicación colabora con la capacitación del profesional de enfermería. Método: estudio aleatorio mixto con el grupo de control y el grupo de intervención con una muestra de 37 participantes del módulo I (asistente de enfermería) de una escuela técnica privada en el interior del estado de São Paulo. Se aplicó a los participantes para completar los instrumentos que contienen datos sociodemográficos, la HCAT (Health Communication Assessment Tool) que evalúa la comunicación de la salud y la Escala de Satisfacción del Estudiante y la Confianza en el Aprendizaje para verificar cuantitativamente la satisfacción y el aprendizaje del estudiante. Utilizando simulación clínica en comunicación. Posteriormente, se llevó a cabo una entrevista con los participantes seleccionados, que se registró para un análisis cualitativo utilizando una referencia teórica. Resultados: El análisis cuantitativo de la escala de satisfacción demostró que los estudiantes estaban muy seguros y satisfechos con su aprendizaje, pero los resultados de la evaluación de la capacidad de comunicación (HCAT) mostraron que los estudiantes no estaban preparados para comunicarse adecuadamente. Además, las declaraciones de entrevistas cuando colocan la comunicación aplicada en el contexto de la atención técnica, repetitiva e informativa refuerzan los resultados evidenciados por el HCAT. Conclusiones: un solo escenario de simulación clínica de alta fidelidad no mostró diferencias significativas entre los participantes en el grupo de control versus el grupo de intervención, lo que demuestra que la estrategia debe obtener una mayor apreciación y capacitación de los 
maestros para usarla y ser mejor implementada en las disciplinas y durante todo el curso de enfermería técnica.

Palabras clave: Educación en enfermería. La comunicacion Simulación 


\section{SUMÁRIO}

1. INTRODUÇÃ

1.1 A simulação clínica no ensino em Enfermagem................................................... 16

1.2 A Comunicação em Saúde ................................................................................... 17

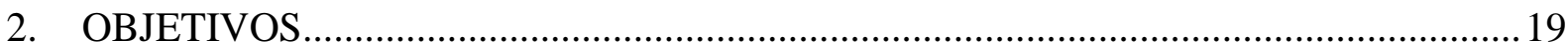

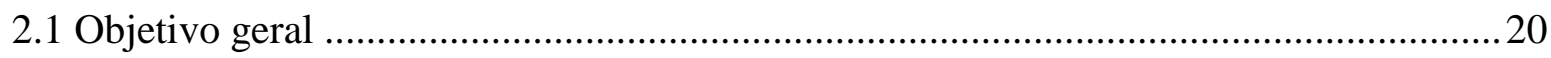

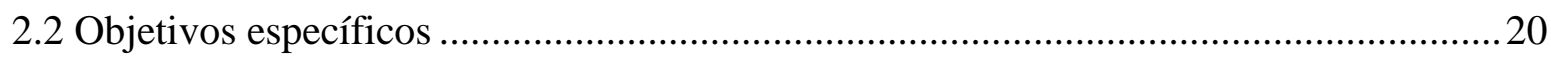

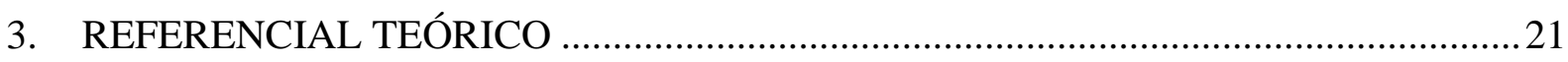

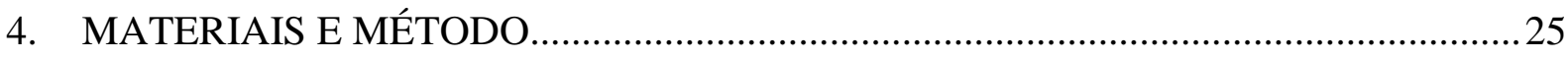

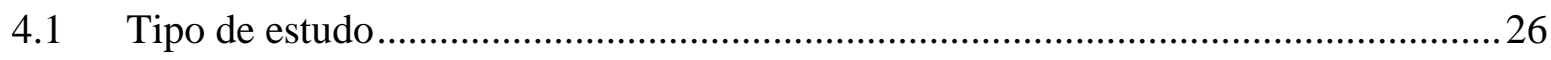

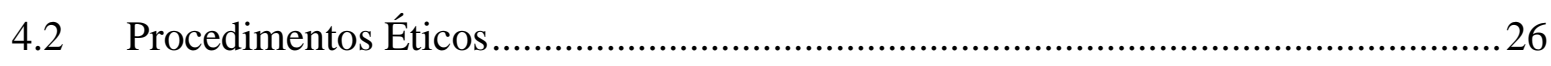

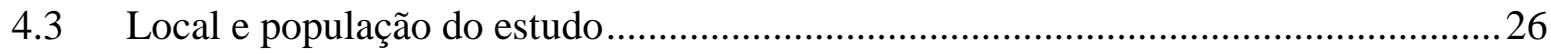

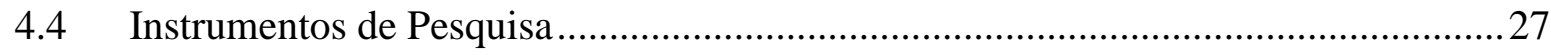

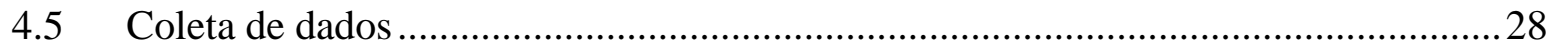

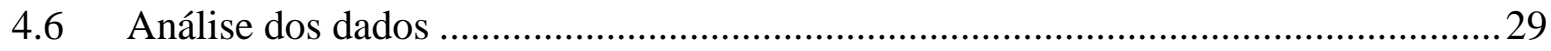

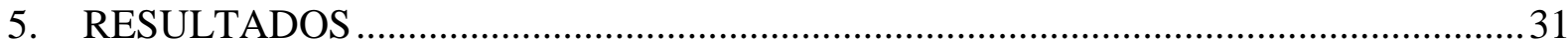

5.1 Etapa 1 - Atividade Teórica de Capacitação em Comunicação em Saúde......................32

5.2 Etapa 2 - Simulação Clínica sobre Comunicação em Saúde.......................................... 33

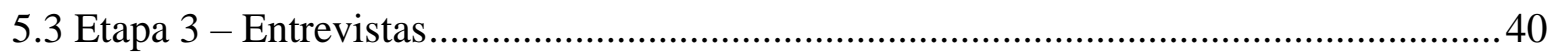

5.3.1. Tema 1 - A comunicação como facilitadora do cuidado procedimental .................... 41

5.3.2. Tema 2 - A comunicação: recurso para o cuidado ou informação?............................ 42

5.4 Análise final dos resultados utilizando a incorporação concomitante ............................43

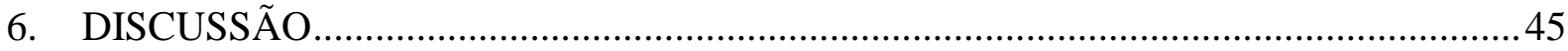

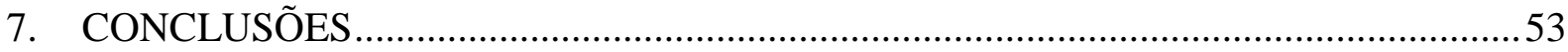

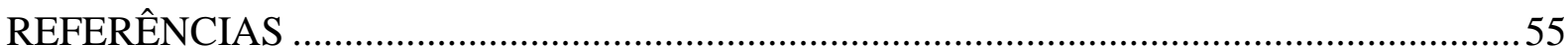

APÊNDICE A - Questionário de caracterização dos participantes da pesquisa ..................67

APÊNDICE B - Plano de Aula em Comunicação em Saúde .............................................6 68

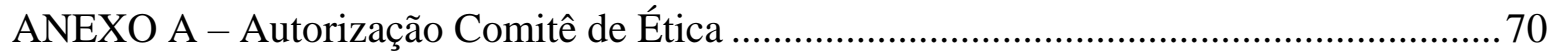

ANEXO B - Ferramenta de Avaliação da Comunicação em Saúde (HCAT) @ ..................73

ANEXO C - Satisfação dos estudantes e autoconfiança na aprendizagem ........................... 75

Autorização para uso da escala de Satisfação dos estudantes e autoconfiança na aprendizagem 
1. INTRODUÇÃO 
A enfermagem brasileira é composta pelas categorias de enfermeiros, técnicos de enfermagem (TE), auxiliares de enfermagem (AE) e parteiras. Desde a década de 80 e após a aprovação da Lei de Diretrizes e Bases da Educação Nacional - LDB (BRASIL, 1996), o número de AE e TE cresceu significativamente no Brasil, passando de 6,6\% para mais de 75\% nos últimos 30 anos (RIBEIRO; PIRES; FLÔR, 2015). De acordo com o Conselho Federal de Enfermagem (COFEN), profissionais com inscrições ativas totalizaram 420.181 AE e 1.190.963 TE, até dezembro de 2018, porém profissionais com dupla titulação foram contabilizados mais de uma vez (CONSELHO FEDERAL DE ENFERMAGEM, 2018).

No Brasil, a principal característica da prática profissional dos AE e TE abrange a preservação da vida e saúde da pessoa, família e comunidade, fundamentada em princípios humanos e éticos, tendo como essência a relação interpessoal (BRASIL, 1986). Juntamente com seus princípios, o aumento significativo dos profissionais no contexto em saúde, faz com que torne importante o investimento nessa categoria profissional, a fim de qualificar a atenção em saúde (GÓES et al., 2015; MARIN et al., 2014; TELES, 2014).

Nosso recorte de estudo incide sobre a categoria profissional de AE e TE brasileira ou o "practice nursing" (no exterior), categoria que surgiu primeiro nos Estados Unidos e países como o Canadá e Austrália seguiram seu modelo (PARKER; HILL, 2017).

O profissional practice nursing $(\mathrm{PN})$ em tradução livre - o prático de enfermagem, é aquele que possui compromisso e valores éticos; desenvolvimento contínuo de si mesmo e de outros; responsabilidade pela prática, demonstrando um espírito de colaboração e flexibilidade. A profissão é caracterizada pela descentralização da tomada de decisões clínicas, autonomia aprimorada e relacionamentos colaborativos com profissionais de outras categorias, acrescentando contribuições também para menor exaustação emocional no ambiente de trabalho e segurança (MARK; SALYER; WAN, 2003). A demanda do profissional PN tem avançado devido a sua competência clínica, liderança e eficácia como agentes de mudança, sendo reconhecidos e incorporados na carreira da enfermagem (PARKER; HILL, 2017).

Nos Estados Unidos, Canadá e Austrália a legitimidade dos profissionais PN é reforçada pela valorização das abordagens multiprofissionais, necessidades populacionais e do sistema de saúde, por exemplo, com o crescimento da população idosa e a crescente aparição de doenças crônicas (PARKER; HILL, 2017; HEALE; BUCKLEY, 2015).

Ainda sobre a representatividade da categoria AE e TE no Brasil, cabe destacar a proposta do Ministério da Saúde (MS) Brasileiro de 2018 para abertura de 250 mil vagas voltadas à qualificação de agentes comunitários de saúde (ACS) e de combate à endemia 
(ACE), como TE, denotando a representatividade desta força de trabalho na saúde e na enfermagem, justificando-se assim o investimento de $\mathrm{R} \$ 1,25$ bilhão. A proposta, faz parte da nova Política Nacional de Atenção Básica que busca a ampliação da atribuição profissional, trazendo maior resolutividade aos atendimentos para a população (BRASIL, 2018b). Foi lançada por meio da Portaria $n^{\circ} 83$ de 10 de janeiro de 2018 que institui o Programa de Formação Técnica para Agentes de Saúde - PROFAGS, para oferta de curso de formação técnica em enfermagem para ACS e ACE no âmbito do Sistema Único de Saúde (SUS), para o biênio de 2018-2019. (BRASIL, 2018a).

Sobre a legislação para formação do AE e TE brasileiros, as instituições de educação profissional técnica de nível médio em enfermagem respondem a Lei Federal no 9.394/96 LDB (BRASIL, 1996) e as Diretrizes Curriculares Nacionais (DCN) para a Educação Profissional Técnica de Nível Médio (EPTNM) (resolução n.6 de 20 de setembro de 2012) da Câmara de Educação Básica do Conselho Nacional de Educação (BRASIL, 2012a).

A LDB (BRASIL, 1996) e as DCN para a EPTNM (BRASIL, 2012a), ao reconhecerem esta modalidade de educação e ensino propuseram uma tentativa de reformulação e mudanças no contexto da formação, buscando promover a organização de conteúdos e inserção de metodologias inovadoras (BRASIL, 1996; BRASIL, 2012; COSTA et al., 2015).

O panorama atual mostra que, apesar de iniciativas governamentais e sociais na busca de mudanças para atender as necessidades de formação inicial de AE e TE qualificados para o atendimento das necessidades em saúde individual e coletiva, muitos cursos de formação ainda utilizam estruturas curriculares fechadas, professores despreparados, metodologias de ensino e materiais pedagógicos que não estimulam pensar, refletir e propor mudanças e intervenções visando a transformação das práticas em saúde (OLIVEIRA et al., 2017; GÓES et al., 2015). É premente a transformação na formação em saúde e estabelecimento de critérios de mudança de natureza pedagógica, política, social e econômica (TAVARES et al., 2016).

As DCN para a EPTNM não fazem referências claras às questões relacionadas ao processo ensino-aprendizagem e dão autonomia às instituições de ensino para construção do seu Projeto Político Pedagógico (PPP), o que por sua vez, pode ocasionar escolhas pedagógicas que não garantem a participação ativa dos alunos, funcionários e professores para uma construção coletiva e democrática (COLONI et al., 2016).

Cabe ressaltar que a formação técnica no Brasil está pautada no princípio da competência profissional para o desempenho eficiente e eficaz de atividades requeridas essencialmente para o trabalho (GÓES et al., 2015). 
Assim, um dos maiores desafios da formação na EPTNM implica na dificuldade de relacionar a visão estritamente tecnicista com a construção social e histórica; Esta dificuldade provém de um modelo de formação técnica que prioriza a clínica hospitalar em detrimento do cuidado comunitário e promoção de saúde (XIMENES et al., 2016; LAZZARI et al., 2011).

A transformação do ensino visando a reorientação de práticas de cuidado à saúde pode acarretar melhor desempenho dos profissionais e dos sujeitos envolvidos no processo, tais como estudantes, docentes, gestores e população além do próprio fortalecimento do saber da enfermagem (SOUSA et al., 2015; TAVARES et al., 2016). Para que o processo educativo seja efetivo, buscam-se métodos ativos de ensino que permitam a prática pedagógica ética, crítica, reflexiva e transformadora, que ultrapasse limites do treinamento em si, focando em metodologias inovadoras para alcançar melhorias no ensino (SOUSA et al., 2018; TAVARES et al., 2016).

Entre as diversas possibilidades de práticas educativas ativas, outro recorte do objeto do estudo se trata da simulação clínica, que tem sido considerada uma estratégia de ensino relevante para a formação em enfermagem ao incrementar o processo de ensino-aprendizagem por consolidar e ampliar as competências e habilidades do aprendiz em diversos assuntos com contextos reais simulados (ALEXANDER et al., 2018; OLIVEIRA et al., 2018; HALLIN et al., 2016) É evidenciado que seu uso junto ou não de tecnologias são estratégias que articulam práticas de ensino e que pesquisas são necessárias na qualificação dos profissionais da saúde, em ambiente controlado com ausência de riscos aos participantes (HALLIN et al., 2016; COSTA et al., 2015; QUIRÓs; VARGAS, 2014).

Considerando a importância de estratégias de ensino para a formação de profissionais de enfermagem críticos e reflexivos, o uso de ambientes simulados no ensino e, dada a importância de que se reveste o papel desempenhado pelo professor no desenvolvimento de tais capacidades, pareceu necessário explorar de que maneira a simulação contribui para aprendizagem do estudante AE e TE.

Assim, diante da relevância da atuação dos AE e TE na saúde brasileira temos interesse em estudar a simulação clínica na EPTNM em enfermagem como mais uma possibilidade de estratégia de ensino-aprendizagem. Assim questiona-se: a aplicação de uma atividade de simulação clínica de alta fidelidade com uso de atores, previamente ao contato do estudante com prática de estágio, favorecerá a comunicação dos alunos com o paciente e/ou família durante o ensino prático? 


\subsection{A simulação clínica no ensino em Enfermagem}

As simulações clínicas têm sido um recurso muito utilizado no ensino de enfermagem, especialmente na última década, pois são definidas como atividades ou eventos que replicam o ambiente da prática clínica (JEFFRIES, 2005) em um ambiente controlado e que integram o mundo real ao processo ensino-aprendizagem de modo a atingir os objetivos de ensino (ARTHUR; LEVETT-JONES; KABLE, 2013). Os ambientes de simulação são uma poderosa estratégia para o encorajamento de estudantes de enfermagem a pensar, agir e refletir já como profissionais (CAMPBELL, 2012, 2013).

$\mathrm{Na}$ formação dos profissionais de saúde, a simulação clínica pode colaborar em um processo de aprendizagem que estimula diversas habilidades atitudinais, procedimentais e cognitivas (ALMEIDA et al., 2016; BRANDÃO; COLLARES; MARIN, 2014), o que leva a elaboração de conceitos multidisciplinares e globais para que o indivíduo seja formado para o mundo de trabalho de forma dinâmica e inovadora (JEFFRIES, 2007; MAZZO et al., 2017).

A simulação clínica tem sido vislumbrada como um potencializador da prática do cuidado em saúde de qualidade. Nesta direção, o MS tem apostado no uso da simulação clínica para qualificação da formação de competências de alunos e profissionais no SUS, por meio de oficinas de Competências e Simulação (ORGANIZAÇÃO PAN-AMERICANA DE SAÚDE, 2015). Trata-se de um projeto de colaboração mais amplo nos âmbitos de gestão, formação e desenvolvimento de recursos humanos do SUS, juntamente com a Secretaria de Igualdade, Saúde e Políticas Sociais do Governo Autonômico da Andaluzia e a Organização Pan-Americana da Saúde (OPAS), a fim de propiciar melhorias de formação dos profissionais e qualificação da assistência à saúde prestada aos cidadãos (ORGANIZAÇÃO PANAMERICANA DE SAÚDE, 2015).

$\mathrm{Na}$ atualidade, considerando pressupostos éticos, de segurança, qualidade, desenvolvimento de tecnologias e constante mutação dos cenários práticos, a simulação vem sendo considerada uma estratégia imprescindível, pois os aprendizes podem participar das aulas teóricas e práticas, com simulações em laboratório e só posteriormente, desenvolverem os primeiros cuidados aos pacientes quando estiverem em instituições de saúde, garantindo a segurança do paciente (CAMACHO, 2010; LEIGH, 2008; SIRC, 2016; TEIXEIRA; FELIX, 2011).

Em se tratando da elaboração e aplicação de cenários para a simulação clínica, os mesmos devem ser delimitados e configurados previamente para reprodução da forma mais fidedigna da realidade clínica, ou seja, o seu planejamento necessita ser baseado nos objetivos 
de aprendizagem (FABRI et al., 2017). O uso da simulação no ensino impacta sobre os recursos que serão utilizados, por exemplo, recursos humanos e materiais, o que determina se o cenário será de média ou alta fidelidade (OLIVEIRA, 2014; SCALABRINI; FONSECA; BRANDÃO, 2017).

Na elaboração de cenários para simulação clínica, além do objetivo de aprendizagem, as metas devem ser descritas, além das informações necessárias ao desenvolvimento das atividades dos aprendizes antes da realização da simulação. Não é recomendado o uso de mais de três objetivos de aprendizagem para cada cenário simulado, os quais devem ter duração compreendida em cerca de vinte minutos (FABRI et al., 2017; JEFFRIES, 2007).

A simulação pode incluir diversos objetos como o uso de jogos, modelos anatômicos, manequins, estudos de casos e apresentações de multimídia. As simulações clínicas geralmente utilizam manequins (simuladores) e/ou pacientes simulados e propõem a aquisição de habilidades destinadas ao desenvolvimento dos cuidados com os pacientes (NEGRI et al., 2017; TEIXEIRA; FELIX, 2011).

No desenvolvimento de cenários de simulação, a dramatização é um recurso conveniente para aprimoramento de profissionais com pensamento crítico e reflexivo, julgamento clínico e tomadas de decisões, além de não ter um custo elevado (NEGRI et al., 2017). Além disso, o uso dos atores em cenários simulados adiciona realismo e podem ser utilizados para preparação de estudantes em situações que envolvam estresse, possibilitando desafios psicológicos semelhantes a situações reais de ambiente de trabalho (IGNACIO et al., 2015; NEGRI et al., 2017).

\subsection{A Comunicação em Saúde}

A comunicação pode ser definida como interação entre seres humanos e é expressa por meio da fala, sendo essa considerada comunicação de aspecto verbal. A comunicação escrita, comportamental, de gestos, toque, entre outras, são consideradas como comunicação nãoverbal (CORIOLANO-MARINUS et al., 2014). É um processo no qual ocorre o compartilhamento e a compreensão de mensagens enviadas e/ou recebidas, que desempenha uma influência no comportamento e no futuro das pessoas envolvidas por meio do conteúdo das mensagens e de como são transmitidas (BARBOSA et al., 2016).

A efetividade em comunicar-se é fundamental no cotidiano do profissional de saúde, para que não haja ruídos ou mal-entendidos. A garantia dessa efetividade, depende do uso de 
técnicas relacionadas a expressões, como por exemplo, o silêncio, a verbalização, aceitação da mensagem recebida, ouvir reflexivamente e verbalização de interesse, além de outras técnicas relacionadas à clarificação e a validação da informação (BARBOSA et al., 2016; CORIOLANO-MARINUS et al., 2014).

A partir do interesse pelo estudo acerca de ensino e avaliação da comunicação em saúde com AE e TE brasileiros, foi realizada uma busca na literatura em duas bases de dados: National Library of Medicine (PubMed) e Literatura Latino-Americana e do Caribe em Ciências da Saúde (LILACS); foram utilizados os descritores "Avaliação", "Comunicação" e "Educação técnica em enfermagem", resultando no total de zero artigos nos últimos cinco anos. Tal situação denota uma lacuna de conhecimento para a formação desta categoria profissional, a qual compreende cerca de $80 \%$ dos profissionais de saúde que atuam na enfermagem (CONSELHO FEDERAL DE ENFERMAGEM, 2018).

A partir do exposto, compreende-se que a aprendizagem da comunicação é essencial para a prática clínica do profissional em enfermagem. Assim tem-se como hipótese: a simulação clínica utilizando atores pode melhorar o conhecimento e a confiança na comunicação de estudantes de enfermagem com paciente/família durante a atividade prática? Os alunos que participaram da simulação terão confiança e desempenho superior aos estudantes não participantes durante as atividades de aprendizagem prática? 
2. OBJETIVOS 


\subsection{Objetivo geral}

$\checkmark$ Verificar se a simulação clínica em comunicação colabora com a formação de estudantes da educação profissional técnica de nível médio em enfermagem.

\subsection{Objetivos específicos}

$\checkmark$ Avaliar as habilidades de comunicação de estudantes da educação profissional técnica de nível médio em enfermagem em um cenário simulado sobre comunicação utilizando atores;

$\checkmark$ Avaliar a autoconfiança na aprendizagem e satisfação percebida dos estudantes da educação profissional técnica de nível médio em enfermagem para se comunicar com paciente e família. 
3. REFERENCIAL TEÓRICO 
A educação consolida-se na transformação do ser que intervém na realidade e que também é alterado por ela. O processo educativo motiva o homem à percepção de que não possui todo o conhecimento e de que é necessário elaborar e investir constantemente em sua atuação, com assimilação de novos conhecimentos e atualização dos saberes já existentes (SOUSA et al., 2015).

Formar profissionais com competência técnica e política, dotados de conhecimento, raciocínio, percepção e sensibilidade para as questões da vida e da sociedade, capacitados para intervir em contextos de incertezas e complexidade, constitui um grande desafio do processo de formação. Dessa maneira, o uso de métodos ativos de aprendizagem ancorados em aprendizagem significativa pode contribuir para obtenção de resultados de aprendizagem (MEIRA; KURCGANT, 2016; WINTERS; PRADO; HEIDEMANN, 2016).

Entende-se que a cognição é baseada no mecanismo de processamento de informações, ou seja, o conhecimento é construído por meio de interação entre o sujeito e objeto. $\mathrm{O}$ professor atua como um problematizador que faz com que o estudante vivencie situações nas quais a interação sujeito-objeto possa ocorrer, tornando-se um sujeito ativo no processo de ensino-aprendizagem (GOMES et al., 2008).

Nesta linha, David Ausubel propõe que a aprendizagem é mais eficiente em ocasiões que o estudante consiga agregar e incorporar os novos conteúdos aos conceitos previamente organizados, por meio da Teoria da Aprendizagem Significativa (GOMES et al., 2008). Portanto, para fins desta pesquisa optamos por utilizar o referencial da aprendizagem significativa.

A aprendizagem significativa ocorre por meio de processos de assimilação. Em tais processos existe a ancoragem seletiva do material de aprendizagem às ideias relevantes existentes na estrutura cognitiva, ou seja, acontece a interação entre as novas ideias apresentadas e as ideias relevantes existentes, levando a compreensão do significado das primeiras como resultado da interação, o que caracteriza o processo de retenção - condição primordial para que se construa o aprendizado. Porém, para caracterizar uma aprendizagem significativa, o conteúdo deve apresentar coerência e ser psicologicamente relevante, sendo considerada a coerência, a evidência e a experiência de cada indivíduo (SOUSA et al., 2015).

A aprendizagem significativa utiliza meios variados, sendo destacados a "diferenciação progressiva" e a "reconciliação integrativa". A diferenciação progressiva refere-se aos conceitos que interagem com os novos conhecimentos e servem de base para a atribuição dos novos significados que se modificam em função da interação. Por sua vez, a reconciliação 
integrativa consiste no estabelecimento de relações entre as ideias, conceitos e proposições existentes estruturalmente (GOMES et al., 2008).

As principais características da teoria da aprendizagem significativa são a não arbitrariedade, ou seja, a relação lógica e relevante entre novas ideias e ideias existentes, servindo de base para incorporação, compreensão e fixação dos novos conhecimentos cognitivos do estudante. Para que a aprendizagem significativa seja efetiva, David Ausubel propõe três condições fundamentais, sendo: as características do material a ser estudado; o desenvolvimento da estrutura cognitiva e a disposição para aprender (CARVALHO et al., 2015).

O uso de organizadores prévios, recomendado por Ausubel, trata-se de materiais introdutórios que são apresentados antes de o conteúdo ser aprendido, podendo ser por meio de vídeos, filmes, cartazes, desde que façam parte da vivência do aprendiz, fazendo com que ocorra a "ancoragem" natural com o existente de sua estrutura cognitiva (SILVA; ZARA, 2018).

Torna-se fundamental na busca da aprendizagem significativa efetiva a postura do professor, que precisa compreender o aprendiz como sujeito da aprendizagem, capaz de pensar, construir, propor, discordar, etc. (RIBEIRO; RIBEIRO, 2018).

Torna-se o foco da Teoria da Aprendizagem Significativa as modificações sofridas na estrutura cognitiva do aprendiz ao relacionar as novas informações com informações já existentes, conhecida como "subsunçor". O termo subsunçor foi nomeado por Ausubel como um conjunto organizado de conceitos, proposições ou ideias já existentes na estrutura cognitiva que servem como âncoras para novo conteúdo de material instrucional. Ou seja, quando as novas informações são apresentadas, estas geram a interação com os subsunçores presentes na estrutura cognitiva, que será modificada de modo com que o aprendiz passe a “enxergar” o que não conseguia anteriormente (GONZALES; ROSA, 2014).

De acordo com conteúdo supracitado, o conteúdo do material a ser estudado e relacionado pelo aprendiz deve possuir significância satisfazendo a três condições, sendo: atendimento ao interesse dos alunos pelo assunto; definição dos subsunçores necessários para aprender o conteúdo proposto no material e ser organizado de forma adequada. Sendo o material potencialmente significativo dentro dos critérios lógicos, o aprendiz obterá a relação com a estrutura cognitiva existente com a nova de maneira substantiva e não arbitrária, gerando a construção de conhecimento (GONZALES; ROSA, 2014).

A aprendizagem significativa possui vantagens notáveis, seja por enriquecimento da estrutura cognitiva do aluno como do ponto de vista da lembrança posterior e da utilização 
para experimentação de novas aprendizagens. Outras vantagens são: o conhecimento adquirido de maneira significativa é retido e lembrado por maior quantidade de tempo; aumento da capacidade de aprender outros conteúdos de maneira mais fácil mesmo se a informação original for esquecida e facilita a aprendizagem seguida, a "reaprendizagem" (PELIZZARI et al., 2002).

Com a aprendizagem significativa, a integração de novas informações facilita a aplicação do conhecimento em atividades que exige maior complexidade de raciocínio do aprendiz, por exemplo, a apreciação de casos clínicos, importantes para os estudos na área da saúde (GOMES et al., 2008). 
4. MATERIAIS E MÉTODO 


\subsection{Tipo de estudo}

Trata-se de um estudo misto incorporado, no qual os dados quantitativos e qualitativos foram coletados concomitantemente. Os achados principais foram aqueles compostos pelos instrumentos de pesquisa, de análise quantitativa; os dados secundários tratou-se das entrevistas, de caráter qualitativo, com o propósito de ampliar e aprofundar o entendimento e a corroboração dos resultados principais (CRESWELL; CLARK, 2015). Foi selecionado este tipo de estudo para que os objetivos fossem contemplados com participação ativa dos participantes.

\subsection{Procedimentos Éticos}

Este estudo foi submetido e aprovado pelo Comitê de Ética em Pesquisa (CEP) da Escola de Enfermagem de Ribeirão Preto, protocolo $\mathrm{n}^{\mathbf{0}} 2.739 .671$ e CAAE 89840418.1.0000.5393 (Anexo A).

Conforme previsto na Resolução do Conselho Nacional de Saúde (CNS) 466/2012, (BRASIL, 2012b) os participantes foram convidados a participarem do estudo e formalizaram o seu aceite, mediante a assinatura do Termo de Consentimento Livre e Esclarecido (TCLE). Foi mantido o anonimato dos participantes e a confidencialidade dos dados coletados em todas as fases da pesquisa além da liberdade de interrupção em qualquer etapa de realização do estudo.

Considerando que uma etapa do estudo foi desenvolvida em uma instituição de saúde Santa Casa de Misericórdia, foi solicitada autorização do local para que o pesquisador observasse e entrevistasse os alunos durante a atividade de ensino prático. Do mesmo modo, o pesquisador não teve contato com os pacientes ou familiares da instituição de saúde.

\subsection{Local e população do estudo}

As etapas 1 e 2 da pesquisa foram desenvolvidas em uma instituição de EPTNM para formação de AE e TE (Módulo I - AE; Módulo II - TE), privada, do interior do Estado de São Paulo, que contava com quatro turmas de aproximadamente 35 alunos em cada uma delas.

A amostra desse estudo foi composta por todos os alunos de uma turma do Módulo I com aproximadamente 40 alunos, maiores de 18 anos, matriculados regularmente na 
instituição de ensino (ou seja, sem pendências em disciplinas anteriores). Foram exclusos alunos que durante o período de realização da coleta de dados não compareceram às atividades de ensino prático ou realizaram o trancamento de matrícula.

Fez-se a opção por uma amostra por conveniência para que os objetivos da pesquisa fossem cumpridos, caracterizada como amostragem não-probabilística, que tem como característica principal não fazer uso de formas aleatórias de seleção. O pesquisador então, seleciona elementos a que tem acesso, que se mostrem mais acessíveis, colaborativos ou disponíveis para participar do processo, sendo considerados adequados e justificados para estágios exploratórios da pesquisa, como uma base para geração de hipóteses e insights e para estudos conclusivos nos quais o pesquisador aceita os riscos da imprecisão dos resultados (FREITAG, 2018).

A última etapa (3) foi realizada no local onde os alunos realizaram as atividades de ensino prático. Tratou-se de uma Santa Casa de Misericórdia que contava com setores de enfermarias clínicas e cirúrgicas, maternidade, pediatria, unidade de emergência, centro cirúrgico, central de materiais, UTI neonatal e pediátrica e UTI geral. As entrevistas foram realizadas no campo da enfermaria clínica e cirúrgica, local de estágio dos alunos que participaram das etapas 1 e 2 da pesquisa.

\subsection{Instrumentos de Pesquisa}

Os instrumentos utilizados para coleta de dados foram constituídos de:

a) Questionário autoaplicável: caracterização sociodemográfica dos participantes da pesquisa (apêndice A) - etapa 2;

b) Instrumento aplicado pelo pesquisador (anexo B): Health Communication Assessment Tool $(H C A T)$ - avalia a comunicação em saúde. Escala likert em cinco pontuações entre "concordo fortemente" e "discordo fortemente" de afirmações relacionadas à comunicação em saúde de profissionais/alunos para pacientes e familiares. O HCAT foi adaptado culturalmente para o Brasil (REIS et al., 2018) e já utilizado em estudo publicado (GÓES et al., 2017) - etapa 2;

c) Instrumento autoaplicável: Escala de Satisfação de Estudantes e Autoconfiança na Aprendizagem (anexo C), criada pela National League for Nursing, traduzida, adaptada e validada para o Brasil (ALMEIDA et al., 2015). Composta por 13 itens, likert de 05 pontos e dividida entre satisfação (05 itens) e autoconfiança (08 itens) do indivíduo para simulações de alta fidelidade - etapa 2; 
d) Entrevista: os participantes foram entrevistados em campo de estágio após terem realizado uma atividade de comunicação com paciente. Para tanto foram realizadas as seguintes perguntas: 1) O que foi mais fácil para você durante o tempo que conversou com o paciente? Por quê? 2) E o que foi mais difícil? Por quê? - etapa 3.

\subsection{Coleta de dados}

A coleta de dados foi dividida em três etapas. Na primeira, os pesquisadores realizaram uma atividade teórica sobre comunicação; na segunda foi realizada a simulação clínica com atores e, na terceira os pesquisadores realizaram a entrevista em campo de estágio em unidade hospitalar.

A etapa 1 da pesquisa constituiu-se no convite a todos os alunos de uma turma do módulo I para participarem de uma atividade teórica/prática de capacitação em saúde, com anuência do diretor, específica sobre o tema comunicação em saúde.

Na etapa 2, aqueles que participaram da etapa 1, foram divididos em dois grupos: grupo controle (não participaram da simulação) e o grupo intervenção, os quais foram convidados para vivenciarem em duplas um cenário de simulação clínica com atores sobre comunicação em momentos previamente agendados. Durante a simulação, dois auxiliares da pesquisa aplicaram o HCAT para avaliar a comunicação em saúde dos participantes, treinados para este fim; após todas as etapas da simulação os participantes responderam a Escala de Satisfação e Autoconfiança com a Aprendizagem.

Cabe destacar que todas as etapas da simulação foram realizadas, quais sejam, briefing, simulação em si e debriefing. O caso clínico utilizado já foi validado em estudo anterior por três especialistas com avaliação de conteúdo, constando os itens objetividade, linguagem, conteúdo, aplicabilidade e aceitabilidade cultural (OLIVEIRA et al., 2016).

A história desenvolvida para a simulação tratou-se de:

Paciente de 71 anos, pardo, admitido em enfermaria para realização de apendicectomia; foi diagnosticado com Hipertensão Arterial há 22 anos (faz uso de medicação), nega alergias medicamentosas e alimentares, tem sequelas de AVC ocorrido há 6 meses (hemiparesia de face à esquerda e manca na perna esquerda), realiza fisioterapia 2 vezes por semana. Histórico médico: $\mathrm{O}$ paciente foi atendido na unidade de emergência com queixas de dor em QID, vômito e temperatura de $38^{\circ} \mathrm{C}$. Foi diagnosticado com apendicite aguda e encaminhado para o hospital para realização de apendicectomia. Após $2^{\circ}$ dia de PO, apresentou aumento da temperatura para $39,7^{\circ} \mathrm{C}$; diagnosticada infecção decorrente de sítio cirúrgico. Histórico social: o idoso mora sozinho em domicílio e há uma empregada doméstica que trabalha de segunda a sábado (horário comercial). Os filhos se revezam para cuidar do paciente nos finais de semana. O filho trabalha em tempo integral e a filha consegue trabalhar meio período para poder cuidar da mãe no domicílio e também levá-la aos tratamentos que realiza durante a semana. Tratamento clínico: 
Antibioticoterapia com Amicacina e Dipirona, se necessário. (OLIVEIRA et al., 2016).

A situação problema enfrentada pelo aluno participante da simulação foi definida por:

O paciente está no quinto dia de internação em tratamento de infecção decorrente de procedimento cirúrgico, demonstra sinais de cansaço, tristeza e irritabilidade; queixa-se de dores especialmente nos locais de punções venosas anteriores. Está acompanhado pelo familiar que permanece todo o tempo, aparenta estar cansado, preocupado, irritado, pois seria a quarta vez que o paciente estaria sendo "picada" nessa internação e, além disso, não aceita que toquem o paciente para acordá-lo, já que ele não conseguiu dormir bem durante a noite. (OLIVEIRA et al., 2016).

Na etapa 3, participantes do grupo controle e intervenção foram convidados a participar da entrevista (a qual foi gravada), durante a realização das atividades de estágio em campos clínicos. A entrevista foi realizada imediatamente após uma situação de comunicação, a qual foi compreendida, para fins deste estudo, como um diálogo superior a um minuto entre o paciente e o aluno. Conforme afirmado anteriormente, o pesquisador não teve contato com o paciente, a observação da situação de comunicação ocorreu à distância e a entrevista foi realizada em local fechado, destinado para este fim, sem comprometer o cuidado ao paciente/família e a formação prática do estudante de enfermagem.

\subsection{Análise dos dados}

O questionário sociodemográfico foi analisado por meio de estatística descritiva para subsidiar a descrição dos participantes e análise dos achados.

A análise do HCAT do grupo experimental - participantes da simulação, foi feita pela soma de "concordo" + "concordo fortemente" ou "discordo" + "discordo fortemente". Os resultados do HCAT foram analisados individualmente por participante e também por item do instrumento. De acordo com orientação dos autores não é possível estabelecer uma pontuação mínima necessária para considerar a comunicação como boa, ruim ou mista, uma vez que os itens avaliam aspectos diferentes do processo de comunicação.

Para avaliar a satisfação e autoconfiança na aprendizagem do grupo experimental participantes da simulação - foi realizada análise estatística exploratória, frequência e porcentagem.

Os dados dos HCAT e Escala de Satisfação e Autoconfiança com a Aprendizagem foram codificados e digitados duplamente em planilhas do aplicativo Excel, exportados e analisados no software IBM® SPSS® Statistics 25.0 (Statistical Package for Social Science). Foi assumido o nível de significância $\alpha=0,05$. Foi realizado Teste de Wilcoxon para 
Amostras Relacionadas para comparar os valores dos escores da Escala de Satisfação de Estudantes e Autoconfiança na Aprendizagem e do HCAT e a correlação Rô de Spearman.

As entrevistas foram analisadas de acordo com a análise de conteúdo categorial temática, a qual descreve de forma objetiva e sistemática o conteúdo expresso pelos participantes, com finalidade de interpretar os mesmos (BARDIN, 1979). A análise temática desdobra-se em três outros polos cronológicos: pré-análise, exploração do material e tratamento dos resultados obtidos e interpretação (BARDIN, 1979), descritas abaixo:

- Pré-análise - Escolha dos documentos que foram analisados; leitura flutuante, na qual o pesquisador toma contato direto e intenso com o material de campo; compreende a totalidade do universo estudado composto pela exaustividade, representatividade e a homogeneidade; formulação e reformulação de hipóteses e objetivos por meio de leituras exaustivas e que se fazem necessárias as primeiras indagações (BARDIN, 1979).

- Exploração do Material - definição das categorias que são as expressões ou palavras significativas, nas quais serão organizados os conteúdos das falas (BARDIN, 1979).

- Tratamento dos resultados obtidos e interpretação - dados brutos e informações são obtidas por meio de operações estatísticas simples (porcentagens) ou complexas (análise fatorial) (BARDIN, 1979).

Os participantes da entrevista foram apresentados por representação alfanumérica como o exemplo a seguir: A1- GI, ou seja, aluno 1 do grupo de intervenção ou A6 - GC, aluno 6 do grupo controle.

Finalmente, os achados dos instrumentos de pesquisa foram confrontados com a análise das falas dos participantes na entrevista para corroboração ou contestação dos resultados do HCAT e Escala de Satisfação e Autoconfiança com a Aprendizagem. 
5. RESULTADOS 
Os resultados serão apresentados de acordo com cada etapa desenvolvida neste estudo.

\subsection{Etapa 1 - Atividade Teórica de Capacitação em Comunicação em Saúde}

Entre os 40 estudantes matriculados no Módulo I do curso Técnico de Enfermagem, 37 participaram da primeira etapa do estudo.

A atividade de capacitação foi realizada em um único dia, em sala de aula no período das 19h-22h, de acordo com plano de aula (apêndice B), no mês de agosto de 2018.

Os temas abordados foram: definição de comunicação; comunicação verbal e nãoverbal; interação da enfermagem com a comunicação; estratégias de comunicação e escuta ativa e a comunicação como segurança do paciente.

Para execução da atividade optou-se por iniciar com uma aula expositiva dialogada com apoio de apresentação de slides em Power Point ${ }^{\circledR}$. Em seguida, foi sugerido aos participantes uma atividade prática por meio da estratégia "Júri Simulado", com uma situação problema vivenciada no contexto de comunicação em saúde/comunicação na enfermagem com duração de aproximadamente uma hora. A atividade foi aceita pelos alunos e gerou repercussão satisfatória, notada por meio de feedback verbais dos mesmos. A situação problema elencada foi a seguinte: A.B.V., auxiliar de enfermagem é acusada de erro de administração medicamentosa em paciente internada em unidade de emergência do hospital em que presta serviço, o que consequentemente levou a paciente a óbito. Será julgada para acusação de homicídio culposo. O medicamento trata-se de solução glicerinada 12\%, utilizado para procedimentos de enteroclisma ou enema. O mesmo, foi administrado em veia, por meio de cateter venoso central. A auxiliar se justifica dizendo que embalagens eram semelhantes dos frascos de soro glicofisiológico e solução glicerinada e que o rótulo de soro utilizado no hospital estava acima do rótulo de fábrica do frasco, além disso, não era de sua responsabilidade a identificação do medicamento, uma vez que, seu colega de profissão durante a passagem de plantão e troca de turnos solicitou para que ela instalasse o medicamento, pois o mesmo estava atrasado com suas medicações. A ré afirma que foi comunicada pelo colega de trabalho que era uma medicação endovenosa. Assim, a ré se declara inocente alegando que tentou ser prejudicada por colega de profissão que não se comunicou adequadamente com ela, ocasionando o erro.

Após caso apresentado, os advogados de defesa e da promotoria terão 20 minutos para criação de seus argumentos e após, 10 minutos para exposição dos mesmos e questionamento da ré. 
A seguir, jurados serão convidados a discutir o caso em outro local por 10 minutos $e$ retornarão com o veredicto dando encerramento da sessão com absolvição ou condenação da ré.

\subsection{Etapa 2 - Simulação Clínica sobre Comunicação em Saúde}

Participaram 16 estudantes de enfermagem compondo o grupo intervenção. A caracterização sócio demográfica dos estudantes está descrita na tabela abaixo (Tabela 1). 
Tabela 1 - Caracterização sociodemográfica dos estudantes do curso técnico de enfermagem participantes $(\mathrm{n}=16)$

\begin{tabular}{|c|c|c|c|}
\hline Variável & \multicolumn{3}{|c|}{ Porcentagem } \\
\hline Gênero & \multicolumn{2}{|c|}{$\begin{array}{c}\text { Masculino } \\
12,5 \% \\
\end{array}$} & $\begin{array}{l}\text { Feminino } \\
87,5 \%\end{array}$ \\
\hline Grau de escolaridade & $\begin{array}{l}\text { Ensino Médio Incompleto } \\
6,3 \%\end{array}$ & $\begin{array}{c}\text { Ensino Médio Completo } \\
81,3 \%\end{array}$ & $\begin{array}{c}\text { Ensino Superior Incompleto } \\
12,5 \%\end{array}$ \\
\hline Idade (anos) & $\begin{array}{r}15-20 \\
56,4 \% \\
\end{array}$ & $\begin{array}{l}21-30 \\
31,5 \% \\
\end{array}$ & $\begin{array}{c}\text { Mais de } 31 \\
12,6 \%\end{array}$ \\
\hline Estado Civil & $\begin{array}{l}\text { Solteiro } \\
62,5 \%\end{array}$ & $\begin{array}{l}\text { Casado } \\
25,0 \%\end{array}$ & $\begin{array}{l}\text { Divorciado } \\
12,5 \%\end{array}$ \\
\hline Cor/Etnia & $\begin{array}{l}\text { Branco } \\
25.0 \%\end{array}$ & $\begin{array}{l}\text { Negro } \\
12,5 \%\end{array}$ & $\begin{array}{l}\text { Pardo } \\
62,5 \%\end{array}$ \\
\hline Município de Residência & $\begin{array}{l}\text { Sertãozinho } \\
50.0 \%\end{array}$ & $\begin{array}{c}\text { Barrinha } \\
37,5 \%\end{array}$ & $\begin{array}{l}\text { Cruz das Posses } \\
\quad 12,5 \%\end{array}$ \\
\hline $\begin{array}{l}\text { Participação em atividade } \\
\text { de formação } \\
\text { complementar }\end{array}$ & $\begin{array}{c}\operatorname{Sim} \\
06,3 \%\end{array}$ & & $\begin{array}{l}\text { Não } \\
93,8 \%\end{array}$ \\
\hline $\begin{array}{l}\text { Participação em atividade } \\
\text { de Simulação Clínica }\end{array}$ & $\begin{array}{c}\mathrm{Sim} \\
18,8 \%\end{array}$ & & $\begin{array}{c}\text { Não } \\
81,3 \%\end{array}$ \\
\hline $\begin{array}{l}\text { Participação anterior em } \\
\text { ensino prático relacionado } \\
\text { ao curso técnico de } \\
\text { enfermagem }\end{array}$ & $\begin{array}{c}\text { Sim } \\
87,5 \%\end{array}$ & & $\begin{array}{c}\text { Não } \\
12,5 \%\end{array}$ \\
\hline $\begin{array}{l}\text { Percepção de dificuldade } \\
\text { em comunicar-se }\end{array}$ & $\begin{array}{c}\mathrm{Sim} \\
43,8 \%\end{array}$ & & $\begin{array}{l}\text { Não } \\
56,3 \%\end{array}$ \\
\hline
\end{tabular}

Fonte: elaborada pelo autor 
A etapa 2 foi realizada apenas com os integrantes do grupo intervenção, por meio da participação em duplas em uma atividade de simulação clínica, de acordo com o caso clínico previamente apresentado. Esta etapa foi realizada em um único dia, com intervalo de uma semana após a etapa 01, no mês de agosto de 2018.

No prebriefing, era apresentado o cenário de uma unidade de enfermagem, os materiais e recursos disponíveis e relatada a situação problema para as duplas.

Na execução do cenário, participaram dois atores que representaram o paciente e seu familiar, os quais foram treinados previamente. Neste momento procedeu-se o preenchimento do HCAT pelos pesquisadores.

Após a realização do cenário, foi realizado o debriefing com os participantes abrangendo os sentimentos, pontos satisfatórios e pontos a serem mais bem desenvolvidos. Ao final, os participantes preencheram o instrumento de caracterização socio demográfica e o de satisfação dos estudantes e autoconfiança na aprendizagem.

A avaliação da habilidade de comunicação dos estudantes está apresentada na tabela 2 de acordo com cada afirmação do HCAT. Na tabela 3, apresenta-se os dados de satisfação dos estudantes e autoconfiança na aprendizagem. 
Figura 1 - Desenvolvimento do Cenário Simulado com Atores
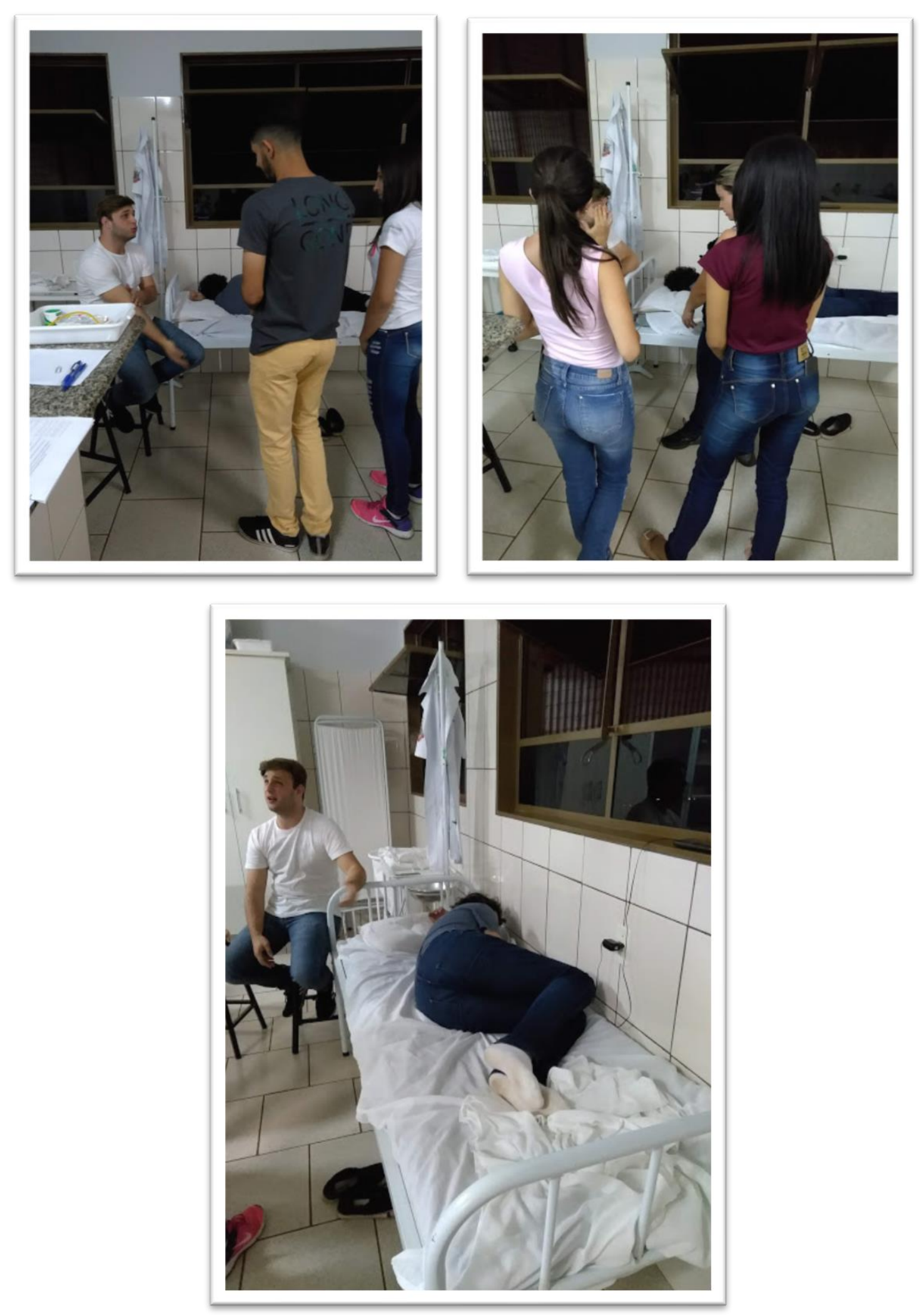

Fonte: arquivo pessoal do autor. 
Tabela 2 - Frequências, porcentagem, média e mediana por afirmação do HCAT

\begin{tabular}{|c|c|c|c|c|c|c|c|}
\hline Afirmação HCAT & 1 & 2 & 3 & 4 & 5 & Média & Mediana \\
\hline A1 - O estudante/profissional apresentou-se ao paciente e/ou família; & $\begin{array}{c}03 \\
18,8 \% \\
\end{array}$ & $\begin{array}{c}03 \\
18,8 \%\end{array}$ & $\begin{array}{c}02 \\
12,5 \%\end{array}$ & $\begin{array}{c}04 \\
25,0 \%\end{array}$ & $\begin{array}{c}04 \\
25,0 \%\end{array}$ & 3,19 & 3,50 \\
\hline $\begin{array}{l}\text { A2 - O estudante/profissional apertou a mão do paciente e/ou família ou cumprimentou } \\
\text { apropriadamente; }\end{array}$ & $\begin{array}{c}03 \\
18,8 \%\end{array}$ & $\begin{array}{c}02 \\
12,5 \%\end{array}$ & $\begin{array}{c}04 \\
25,0 \%\end{array}$ & $\begin{array}{c}02 \\
12,5 \%\end{array}$ & $\begin{array}{c}05 \\
31,3 \%\end{array}$ & 3,25 & 3,00 \\
\hline A3 - O estudante/profissional explicou a razão da sua visita em termos apropriados; & $\begin{array}{c}04 \\
25,0 \%\end{array}$ & $\begin{array}{c}08 \\
50,0 \%\end{array}$ & $\begin{array}{c}03 \\
18,8 \%\end{array}$ & - & $\begin{array}{c}01 \\
06,3 \%\end{array}$ & 2,13 & 2,00 \\
\hline $\begin{array}{c}\text { A4 - O estudante/profissional usou comunicação positiva, incluindo um sorriso para encorajar as } \\
\text { interações; }\end{array}$ & $\begin{array}{c}02 \\
12,5 \%\end{array}$ & $\begin{array}{c}08 \\
50,0 \%\end{array}$ & $\begin{array}{c}05 \\
31,3 \%\end{array}$ & 01 & - & 2,31 & 2,00 \\
\hline A5 - O estudante/profissional manteve contato visual enquanto conversava com o paciente; & $\begin{array}{c}07 \\
43,8 \%\end{array}$ & $\begin{array}{c}07 \\
43,8 \%\end{array}$ & $\begin{array}{c}01 \\
06,3 \%\end{array}$ & $\begin{array}{c}01 \\
06,3 \%\end{array}$ & - & 1,75 & 2,00 \\
\hline A6 - O estudante/profissional comunicou o que estava prestes a fazer ANTES de fazê-lo; & $\begin{array}{c}07 \\
43,8 \%\end{array}$ & $\begin{array}{c}06 \\
37,5 \%\end{array}$ & $\begin{array}{c}02 \\
12,5 \%\end{array}$ & $\begin{array}{c}01 \\
06,3 \%\end{array}$ & - & 1,81 & 2,00 \\
\hline $\begin{array}{l}\text { A7 - O estudante/profissional perguntou ao paciente ou familiar se poderia tocar o paciente ANTES } \\
\text { de fazer um procedimento ou exame (pressão arterial, ausculta, punção venosa, sondagem, etc.) }\end{array}$ & $\begin{array}{c}02 \\
12,5 \%\end{array}$ & $\begin{array}{c}02 \\
12,5 \%\end{array}$ & $\begin{array}{c}02 \\
12,5 \%\end{array}$ & $\begin{array}{c}02 \\
12,5 \%\end{array}$ & $\begin{array}{c}08 \\
50,0 \%\end{array}$ & 3,75 & 4,50 \\
\hline $\mathrm{A} 8-\mathrm{O}$ estudante/profissional tocou o paciente apropriadamente. & $\begin{array}{c}04 \\
25,0 \%\end{array}$ & $\begin{array}{c}07 \\
43,8 \%\end{array}$ & $\begin{array}{c}03 \\
18,8 \%\end{array}$ & $\begin{array}{c}01 \\
06,3 \%\end{array}$ & $\begin{array}{c}01 \\
06,3 \%\end{array}$ & 2,25 & 2,00 \\
\hline A9 - O estudante/profissional passou a maior parte do tempo perto do paciente. & $\begin{array}{c}10 \\
62,5 \%\end{array}$ & $\begin{array}{c}06 \\
37,5 \%\end{array}$ & - & - & - & 1,38 & 1,00 \\
\hline A10 - O estudante/profissional sentou-se ao orientar ou conversar com o paciente. & - & - & - & $\begin{array}{c}06 \\
37,5 \%\end{array}$ & $\begin{array}{c}10 \\
62,5 \%\end{array}$ & 4,63 & 5,00 \\
\hline A11 - O estudante/profissional ouviu mais do que falou. & $\begin{array}{c}03 \\
18,8 \%\end{array}$ & $\begin{array}{c}05 \\
31,3 \%\end{array}$ & $\begin{array}{c}04 \\
25,0 \%\end{array}$ & $\begin{array}{c}04 \\
25,0 \%\end{array}$ & - & 2,56 & 2,50 \\
\hline A12 - O estudante/profissional inclinou-se em direção à pessoa que falava para demonstrar interesse. & $\begin{array}{c}02 \\
12,5 \%\end{array}$ & $\begin{array}{c}06 \\
37,5 \%\end{array}$ & $\begin{array}{c}03 \\
18,8 \%\end{array}$ & $\begin{array}{c}02 \\
12,5 \%\end{array}$ & $\begin{array}{c}03 \\
18,8 \%\end{array}$ & 2,88 & 2,50 \\
\hline $\begin{array}{c}\text { A13 - O estudante/profissional orientou efetivamente o paciente e/ou família sobre o procedimento, } \\
\text { doença e/ou tratamento. }\end{array}$ & 02 & $\begin{array}{c}02 \\
12,5 \%\end{array}$ & $\begin{array}{c}06 \\
37,5 \%\end{array}$ & 06 & - & 3,00 & 3,00 \\
\hline A14 - O estudante/profissional fez perguntas para encorajar o feedback e aumentar a clareza. & 01 & $\begin{array}{c}03 \\
18,8 \%\end{array}$ & $\begin{array}{c}04 \\
25,0 \%\end{array}$ & $\begin{array}{c}05 \\
31,3 \%\end{array}$ & $\begin{array}{c}03 \\
18,8 \%\end{array}$ & 3,38 & 3,50 \\
\hline
\end{tabular}


Conclusão

\begin{tabular}{|c|c|c|c|c|c|c|c|}
\hline Afirmação HCAT & 1 & 2 & 3 & 4 & 5 & Média & Mediana \\
\hline $\begin{array}{l}\text { A15 - O estudante/profissional reconheceu e respondeu apropriadamente a comportamentos verbais e } \\
\text { não-verbais (franzir de testa, lágrimas, histeria, silêncio, etc.) do paciente e/ou família. }\end{array}$ & $\begin{array}{c}03 \\
18,8 \%\end{array}$ & $\begin{array}{c}08 \\
50,0 \%\end{array}$ & $\begin{array}{c}04 \\
25,0 \%\end{array}$ & $\begin{array}{c}01 \\
06,3 \%\end{array}$ & - & 2,19 & 2,00 \\
\hline A16 - O estudante/profissional usou tom de voz e volume apropriados para a situação. & $\begin{array}{c}09 \\
56,3 \%\end{array}$ & $\begin{array}{c}06 \\
37,5 \%\end{array}$ & - & $\begin{array}{c}01 \\
06,3 \%\end{array}$ & - & 1,56 & 1,00 \\
\hline $\begin{array}{l}\text { A17 - O estudante/profissional evitou julgar comportamentos do paciente/família (ex. condição } \\
\text { econômica, abuso, uso de drogas, orientação sexual, religião/diferenças culturais, etc.). }\end{array}$ & $\begin{array}{c}09 \\
56,3 \%\end{array}$ & $\begin{array}{c}07 \\
43,8 \%\end{array}$ & - & - & - & 1,44 & 1,00 \\
\hline $\begin{array}{l}\text { A18 - O estudante/profissional passou um tempo igual ou maior abordando aspectos psicossociais no } \\
\text { cuidado ao paciente/família em relação aos aspectos clínicos (biológicos). }\end{array}$ & $\begin{array}{c}01 \\
06,3 \%\end{array}$ & $\begin{array}{c}01 \\
06,3 \%\end{array}$ & $\begin{array}{c}08 \\
50,0 \%\end{array}$ & $\begin{array}{c}05 \\
31,3 \%\end{array}$ & $\begin{array}{c}01 \\
06,3 \%\end{array}$ & 3,25 & 3,00 \\
\hline $\begin{array}{c}\text { A19 - O estudante/profissional perguntou sobre os sentimentos do paciente/família sobre a situação, } \\
\text { demonstrando preocupação. }\end{array}$ & - & $\begin{array}{c}04 \\
25,0 \%\end{array}$ & $\begin{array}{c}03 \\
18,8 \%\end{array}$ & $\begin{array}{c}08 \\
50,0 \%\end{array}$ & $\begin{array}{c}01 \\
06,3 \%\end{array}$ & 3,38 & 4,00 \\
\hline $\begin{array}{c}\text { A20 - O estudante/profissional reconheceu o conflito e tentou obter informações e encontrar } \\
\text { oportunidades para minimizá-lo ou manejá-lo. }\end{array}$ & $\begin{array}{c}03 \\
18,8 \%\end{array}$ & $\begin{array}{c}11 \\
68,8 \%\end{array}$ & $\begin{array}{c}02 \\
12,5\end{array}$ & - & - & 1,94 & 2,00 \\
\hline $\begin{array}{l}\text { A21 - O estudante/profissional desenvolveu, manteve ou aprimorou relacionamento interpessoal com } \\
\text { o paciente e/ou família (via comunicação e profissionalismo). }\end{array}$ & $\begin{array}{c}03 \\
18,8 \%\end{array}$ & $\begin{array}{c}08 \\
50,0 \%\end{array}$ & $\begin{array}{c}03 \\
18,8 \%\end{array}$ & $\begin{array}{c}02 \\
12,5 \%\end{array}$ & - & 2,25 & 2,00 \\
\hline $\begin{array}{l}\text { A22 - O estudante/profissional evitou termos técnicos de saúde (sinais vitais, punção venosa, etc.). } \\
\text { [inclua abaixo os termos técnicos utilizados]. }\end{array}$ & $\begin{array}{c}01 \\
06,3 \%\end{array}$ & $\begin{array}{c}07 \\
43,8 \%\end{array}$ & $\begin{array}{c}03 \\
18,8 \%\end{array}$ & $\begin{array}{c}03 \\
18,8 \%\end{array}$ & $\begin{array}{c}02 \\
12,5 \%\end{array}$ & 2,88 & 2,50 \\
\hline
\end{tabular}

Fonte: elaborado pelo autor 
Tabela 3 - Frequências, porcentagem, média e mediana por afirmação do instrumento de Satisfação dos estudantes e autoconfiança na aprendizagem

\begin{tabular}{|c|c|c|c|c|c|c|c|}
\hline Afirmação "Satisfação dos estudantes e autoconfiança na aprendizagem" & 1 & 2 & 3 & 4 & 5 & Média & Mediana \\
\hline $\begin{array}{l}\text { 2.A simulação forneceu-me uma variedade de materiais didáticos e atividades para promover a } \\
\text { minha aprendizagem do currículo médico cirúrgico. }\end{array}$ & - & - & 01 & $\begin{array}{c}06 \\
37,5 \%\end{array}$ & $\begin{array}{c}09 \\
56,3 \%\end{array}$ & 4,50 & 5,00 \\
\hline $\begin{array}{l}\text { 4.Osmateriais didáticos utilizados nesta simulação foram motivadores eajudaram-mea } \\
\text { aprender. }\end{array}$ & - & - & $\begin{array}{c}01 \\
06,3 \%\end{array}$ & $\begin{array}{c}03 \\
18,8 \%\end{array}$ & $\begin{array}{c}12 \\
75,0 \%\end{array}$ & 4,69 & 5,00 \\
\hline $\begin{array}{l}\text { 6. Estou confiante de que domino o conteúdo da atividade de simulação que meu professor me } \\
\text { apresentou. }\end{array}$ & - & $\begin{array}{c}02 \\
12,5 \%\end{array}$ & $\begin{array}{c}03 \\
18,8 \%\end{array}$ & $\begin{array}{c}07 \\
43,8 \%\end{array}$ & $\begin{array}{c}04 \\
25,0 \%\end{array}$ & 3,81 & 4,00 \\
\hline $\begin{array}{l}\text { 7. Estou confiante que esta simulação incluiu o conteúdo necessário para o domínio do currículo } \\
\text { médico cirúrgico. }\end{array}$ & 01 & - & $\begin{array}{c}01 \\
06,3 \%\end{array}$ & $\begin{array}{c}07 \\
43,8 \%\end{array}$ & $\begin{array}{c}07 \\
43,8 \%\end{array}$ & 4,19 & 4,00 \\
\hline $\begin{array}{c}\text { 8. Estou confiante de que estou desenvolvendo habilidades e obtendo os conhecimentos } \\
\text { necessários a partir desta simulação para executar os procedimentos necessários em um } \\
\text { ambiente clínico. }\end{array}$ & - & - & $\begin{array}{c}01 \\
06,3 \%\end{array}$ & $\begin{array}{c}04 \\
25,0 \%\end{array}$ & $\begin{array}{c}11 \\
68,8 \%\end{array}$ & 4,63 & 5,00 \\
\hline 11. Eu sei como obter ajuda quando eu não entender os conceitos abordados na simulação. & - & $\begin{array}{c}01 \\
06,3 \%\end{array}$ & $\begin{array}{c}03 \\
18,8 \%\end{array}$ & $\begin{array}{c}07 \\
43,8 \%\end{array}$ & $\begin{array}{c}05 \\
31,3 \%\end{array}$ & 4,00 & 4,00 \\
\hline 12. Eu sei como usar atividades de simulação para aprender habilidades. & - & - & $\begin{array}{c}03 \\
18,8 \%\end{array}$ & $\begin{array}{c}03 \\
18,8 \%\end{array}$ & $\begin{array}{c}10 \\
62,5 \%\end{array}$ & 4,44 & 5,00 \\
\hline $\begin{array}{l}\text { 13.Éresponsabilidade do professor dizer-me o que eu preciso aprender na temática } \\
\text { desenvolvida na simulação durante a aula. }\end{array}$ & 01 & - & $\begin{array}{c}02 \\
12,5 \%\end{array}$ & $\begin{array}{l}05 \\
31,3 \%\end{array}$ & $\begin{array}{c}08 \\
50,0 \%\end{array}$ & 4,19 & 4,50 \\
\hline
\end{tabular}

Fonte: elaborada pelo autor 
Os dados foram analisados em um teste de Wilcoxon para amostras pareadas. O resultado demonstrou que os valores dos escores das escalas HCAT e de satisfação dos estudantes e autoconfiança na aprendizagem tem diferença significante $(\mathrm{p}<0,001)$.

A análise estatística dos achados levou à pesquisadora a interpretação da não confirmação da hipótese de que a participação do estudante em uma única atividade de simulação clínica utilizando atores poderia melhorar o seu conhecimento sobre comunicação em saúde. Contudo, os alunos sentiam-se satisfeitos e autoconfiantes quanto à sua aprendizagem sobre comunicação com paciente/família.

\subsection{Etapa 3 - Entrevistas}

A etapa 3 ocorreu uma semana após o grupo de intervenção terem participado da simulação clínica. No final do mês de agosto e início do mês de setembro de 2018. A pesquisadora permaneceu no local de realização do estágio em dois períodos, manhã e tarde, por 02 dias consecutivos. No presente campo de estágio, os alunos foram divididos pelo colégio em turmas de 10 alunos, somando 20 alunos nos dois períodos. Conforme apresentado anteriormente, chegou-se ao resultado de 10 entrevistas devido a exclusão de participantes pela não aceitação e por falta no estágio.

Nas entrevistas, participaram 10 alunos, sendo seis do grupo intervenção e quatro do grupo controle, que realizaram estágio na Santa Casa de Misericórdia nas enfermarias clínicocirúrgica. Cabe destacar que todos os pacientes internados neste setor eram acompanhados por familiar devido ao grau de dependência física e/ou psicológica.

A pesquisadora realizou observação não participante para determinar o momento adequado de abordagem dos estudantes, ou seja, após uma ação de comunicação entre o estudante e o paciente/família.

Ao fim da observação de diálogo, a pesquisadora convidou os estudantes de forma individual a comparecerem a um ambiente reservado e desprovido de ruídos sonoros para que pudesse realizar a gravação da entrevista. Aos estudantes que aceitaram foi realizada a seguinte pergunta: "O que foi mais fácil para você durante o tempo que conversou com o paciente? Por quê? Após o participante responder à pergunta foi realizada o segundo questionamento: 2) E o que foi mais difícil? Por quê?"”

A duração das entrevistas variou entre 00:25 segundos a 01:49 minutos com média de aproximadamente 0,51 segundos para cada participante. 
Após obter as entrevistas, as mesmas foram transcritas e analisadas individualmente segundo referencial de Bardin (1979).

$\mathrm{Na}$ fase de pré-análise a pesquisadora transcreveu as entrevistas, ouvindo a gravação duas vezes em busca de palavras, pausas ou outros elementos que pudessem compor a transcrição; realizou a leitura flutuante para ter o primeiro contato direto e intenso com os dados; leu exaustivamente o material em busca de elementos que representassem as falas dos participantes de forma homogênea para realizar as primeiras hipóteses sobre o material construído. Esta etapa teve duração de 20 dias e foi realizada de novembro de 2018 a dezembro de 2019.

$\mathrm{Na}$ fase de Exploração do Material foram definidas as categorias e organizados os conteúdos das falas (BARDIN, 1979). Para tanto, foi elaborado um mapa temático, identificando-se a essência de cada tema, verificando o que era interessante e conveniente com a história de cada um deles e, posteriormente, aplicado no contexto da história global para responder à questão de pesquisa. Considerou-se cada tema e a relação entre eles, possuindo uma definição dos mesmos.

No tratamento dos resultados obtidos e interpretação dos achados, a análise final e descritiva do relatório foi realizada aperfeiçoando a escrita, de maneira que ao final consistiu em um relato conciso da história referente aos dados, apresentando argumentos que correspondessem ao objetivo do estudo e integrando-os com a literatura pertinente e referencial teórico. Portanto, nesse relatório houve dados suficientes para demonstrar a prevalência dos temas, respondendo às questões de pesquisa.

A partir da análise dos dados e considerando o referencial teórico para interpretação, dois temas emergiram após categorização das informações colhidas: "A comunicação como facilitadora do cuidado procedimental" e "A comunicação: recurso para o cuidado ou informação?"

\subsubsection{Tema 1 - A comunicação como facilitadora do cuidado procedimental}

A partir da análise das entrevistas foi possível identificar que os estudantes sentiam maior facilidade para se comunicar com os pacientes ou familiares em duas situações: 1) durante a realização de cuidado pautado em procedimentos técnico e 2) comunicar-se com pacientes conscientes e comunicativos, não exclusivamente dependentes físico ou psicológicos. Estes achados foram presentes entre os participantes que experenciaram ou não a simulação clínica na etapa 2 do estudo. 
Percebeu-se também que a maior parte dos estudantes se sente mais confortável em comunicar-se com o paciente durante a realização de procedimentos técnicos, como o banho e a verificação de sinais vitais, expresso em seis relatos (60\%). Também se constata que apenas um estudante $(10 \%)$ destacou a questão da confiança em seu relato e que cinco estudantes (50\%) destacaram a condição de consciência e orientação do paciente como um facilitador da comunicação.

Os achados sugerem que a comunicação tem sido utilizada pelos participantes como uma ferramenta para execução do cuidado procedimental, sendo utilizada única e exclusivamente para informar ao paciente sobre procedimentos que serão realizados, de forma tecnicista e repetitiva.

"[...] O que foi mais fácil, pra mim, é... Na hora do banho, né, pra mim tá sendo mais fácil porque tem uns pacientes que são comunicativos então facilita um pouco[...]." (A7- GC)

“[...] O que foi mais fácil foi ver que ele tá em consciente, ele me respondeu consciente, a gente conversou[...]." (A9-GC)

“[...] Mais fácil pra mim é quando o paciente ele tá, ele sabe onde ele se encontra, tá em tempo e espaço e responde as nossas perguntas[...].” (A3-GI)

“[...] O que foi mais fácil pra mim na comunicação com o paciente foi o momento de chegar até ele e ver os sinais vitais, perguntar como ele estava, o que foi feito, o porquê que ele está internado[...]." (A4-GI)

“[...] O mais fácil que foi pra se comunicar com o paciente foi assim, pra poder ele sentar, a gente avisar que ele vai tomar um banho, tudo, (...) mas o mais fácil pra mim foi isso, a comunicação foi a aceitação deles, foi isso pra mim[...].” (A10-GC)

“[...] O que foi mais fácil foi se comunicar na hora de fazer os sinais vitais porque as vezes quando você se comunica melhor com o paciente, o paciente é até mais aberto com você na hora de você fazer o procedimento então isso ajuda bastante[...]." (A5GI)

“[...] O que eu achei mais fácil foi o diálogo, eu tive mais confiança em falar com o paciente[...]." (A6-GI)

\subsubsection{Tema 2 - A comunicação: recurso para o cuidado ou informação?}

Neste tema, três categorias de análises surgiram. Os participantes destacaram sobre frustrações ao: 1) tentarem comunicar-se com pacientes não orientados ou dependentes físico ou mentais, identificados em seis relatos $(60 \%) ; 2)$ na presença de acompanhantes, destacada 
em dois relatos $(20 \%)$; e, 3) na realização de procedimentos considerados complexos tecnicamente ao lidarem com pacientes que são resistentes a uma comunicação apenas informativa, identificada em quatro relatos (40\%).

A inferência feita sobre o uso da comunicação para uma assistência tecnicista ainda se mantem presente neste tema.

"[...] às vezes aquele que não tá ainda tipo conversando, a gente as vezes vai dar um banho, a gente não sabe se o paciente tá com dor, entendeu? [...].” (A7-GC)

"[...]Mas as vezes seria o mais difícil também, que nem todos concordam (acompanhante)[...].” (A10-GC)

"[...]quando o acompanhante tá, você tem que ter comunicação não só com o paciente, com o acompanhante também. E o mais difícil é você conversar com o acompanhante quando o paciente é mais debilitado, porque as vezes ele não aceita que você faça os procedimentos que é necessário pra ajudar o paciente[...].” (A5-GI)

"[...]E minha maior dificuldade é o banho no leito com paciente acamado, que eu "to" tendo um pouco mais de dificuldade, mas com isso tudo é o tempo né, a gente vai aprendendo[...]." (A1-GI)

"[...]foi na hora da troca de fixação porque ele ficava se mexendo e a gente falava com ele e não adiantava muito [...]." (A2-GI)

"[...]foi na parte da medicação, que a gente tem que, é, explicar pra ele, como que é, que vai ser administrado e fazer ele entender o porquê que ele tem que ser, que tem que ser administrado o medicamento[...]." (A4-GI)

Observa-se ainda que os participantes do grupo intervenção não expuseram confiança e desempenho superiores aos participantes do grupo controle durante as atividades de aprendizagem prática, considerando as entrevistas realizadas.

\subsection{Análise final dos resultados utilizando a incorporação concomitante}

Considerando o desenho metodológico adotado neste estudo, qual seja o estudo misto, a utilização da entrevista corroborou para a confirmação dos resultados apontados pela HCAT na qual os estudantes foram avaliados como escores inferiores a 2,5 em 11 itens dos 21 possíveis no HCAT- A3, A4, A5, A6, A8, A9, A15, A16, A17, A20, A21, apesar de se sentirem altamente confiantes e satisfeitos com sua aprendizagem, de acordo com dados apresentados na tabela 2 . 
Das 11 afirmações do HCAT com médias inferiores a 2,5, cinco delas (A3, A6, A15, A20, A21) podem ser reconhecidas nas entrevistas realizadas com participantes do grupo controle e intervenção.

No que se refere a afirmação A3 - explicação da visita no quarto do paciente, percebe-se que apesar do baixo escore no HCAT, os participantes consideram importante a chegada ao quarto e o contato com paciente, por meio dos relatos:

"[...] foi o momento de chegar até ele e ver os sinais vitais, perguntar como ele estava, o que foi feito, o por que ele estava internado” (A4-GI); e “[...] você (aluno) pode conversar com ele (paciente) pra até mesmo fazer com que o procedimento seja realizado de forma melhor" (A5-GI).

Em relação à comunicação do aluno com o paciente/acompanhante sobre o que seria feito (A6), os dados da entrevista mostram que os participantes tiveram oportunidades de comunicação positivas e negativas.

Quando um participante relata que "[...] a gente (aluno) falava com ele (paciente) e não adiantava muito [...]" (A2-GI) há uma clara demonstração de que o aluno participante da grupo de intervenção não conseguiu reconhecer e agir adequadamente aos comportamentos verbais e não verbais do paciente (afirmação 15 do HCAT) apesar de reconhecer o conflito (Afirmação 20 do HCAT).

Em várias falas é possível inferir que o estudante não conseguiu desenvolver um relacionamento interpessoal com o paciente e/ou família (afirmação 21 do HCAT) pois grande parte das falas das entrevistas remetem-se ao uso da comunicação para estabelecimento de cuidado procedimental.

Em relação à escala de satisfação e autoconfiança com a aprendizagem, nas afirmações que se referem à simulação enquanto um método de ensino (de acordo com a escala), os alunos a reconheceram como positiva e adequada para a aprendizagem com médias superiores a 4,5. Contudo, quando o aluno é estimulado a refletir sobre sua confiança em relação ao domínio do conteúdo cognitivo (teórico) e também sobre como obter ajuda quando não sabe um determinado conceito, a média foi inferior a 4. Assim, infere-se também que, apesar da média geral desta escala ter sido superior a 4,5 duas afirmações demonstram que os alunos se sentiram despreparados para aplicar a comunicação em um contexto simulado com atores o que pode ter repercutido na sua atuação real em campo de estágio clínico. 
6. DISCUSSÃO 
Esta pesquisa possibilitou a avaliação da simulação no processo ensino aprendizagem da EPT em enfermagem, no contexto da formação de auxiliares, ao considerar a comunicação como eixo transversal da formação dos profissionais de saúde, na tentativa de contribuir com evidências científicas sobre a aplicação da simulação clínica na formação desta categoria profissional no Brasil.

Os resultados reforçam que apesar do trabalho e assistência em saúde terem passado por transformações ao decorrer dos anos, ainda permanece a formação do técnico de enfermagem de forma disciplinar, conteudista, por meio de método tradicional, cursos pontuais de atualização ou capacitação profissional, que ocorrem geralmente fora da realidade do mundo do trabalho (CARDOSO et al., 2017).

Em geral, as estruturas curriculares dos cursos de enfermagem contam com um quantitativo elevado de conteúdos para serem trabalhados em um curto período de tempo. Além do mais, os alunos têm dificuldade de identificar quais são os conteúdos essenciais para a sua formação, pois as aulas são ministradas de forma homogênea sem ressaltar quais são os conceitos mais relevantes, dificultando que o aluno estabeleça efetivamente a relação entre a teoria e a prática (CARVALHO et al., 2015)

Para que o estudante vivencie o processo de ensino-aprendizagem de forma dinâmica, contemporânea e ativa, torna-se imprescindível a reformulação do modelo pedagógico vigente, que se dará por meio da implementação de um currículo que possibilite o desenvolvimento de competências, as quais estão determinadas nas Diretrizes Curriculares Nacionais (DCN) dos cursos da área da saúde (BRASIL, 2012a; MAKUCH; ZAGONEL, 2017).

As DCN devem se constituir em um direcionamento para o processo de construção do Projeto Político Pedagógico das instituições de ensino, ao determinar elementos e princípios básicos para formação do profissional, flexibilidade na organização dos cursos; princípios de formação integral; uso de metodologias ativas; incorporação de atividades complementares; articulação entre teoria e prática, entre outras (FERNANDES; REBOUÇAS, 2013). A DCN da EPTNM é organizada por eixos tecnológicos, permitindo flexibilidade, diversidade e atualização dos conteúdos, segundo interesses e possibilidades das instituições educacionais (BRASIL, 2012a).

Assim, o eixo norteador dos currículos das instituições de ensino e as composições de cursos devem ser organizados de acordo com a tipologia curricular de cada escola, com suas características próprias, missão, linhas de pensamento do grupo de docentes que atuam no curso, características do perfil do estudante, determinantes regionais de atenção à saúde- 
doença, sistemas de saúde, entre outras que foram propostas no Projeto Pedagógico do Curso (PPC) (MAKUCH; ZAGONEL, 2017).

A instituição de ensino que compôs este estudo está localizada em uma região metropolitana do estado de São Paulo, é privada, sendo a única escola técnica de enfermagem em um município com mais de 100.000 habitantes. De um total de dezenove professores, aproximadamente cinco deles tem formação pedagógica completa. $\mathrm{O}$ curso de técnico de enfermagem tem proposta curricular disciplinar, com habilitação em módulos, modulo um auxiliar de enfermagem e módulo dois - técnico de enfermagem, totalizando 1800 horas, das quais 1200 horas são teóricas e 600 horas de atividades práticas. Em se tratando apenas do módulo auxiliar de enfermagem, a carga horária total do curso é de 1110 horas. As aulas teóricas são ministradas por um ou dois professores e as práticas são realizadas em instituições de saúde do munícipio sob a supervisão de enfermeiros professores, os quais normalmente são enfermeiros assistenciais dos locais de estágio. Os alunos do período diurno têm oportunidade de realizarem estágios em Unidades Básicas de Saúde e hospitais enquanto os alunos do período noturno realizam estágios em Unidades de Pronto Atendimento e hospitais.

Outras escolas tem modelos de formação diferentes, como o modelo por Competências Profissionais organizados dentro de seus módulos, a exemplo do Serviço Nacional de Aprendizagem Comercial de São Paulo - SENAC (SERVIÇO NACIONAL DE APRENDIZAGEM COMERCIAL, 2006); já os Centros Estaduais de Educação Tecnológica Paula Souza - ETEC, opta por módulos formados por componentes curriculares (disciplinas) (CENTRO ESTADUAL DE EDUCAÇÃO TECNOLÓGICA PAULA SOUZA, 2012); as Escolas Técnicas do SUS - ETSUS aplicam o modelo de formação com foco nas necessidade e formação de recursos humanos para o Sistema Único de Saúde (BRASIL, 2017; MATO GROSSO DO SUL, 2008).

Podemos evidenciar então, que as estruturas curriculares das instituições são diferentes por todo o Brasil, não havendo padronização das mesmas em seus PPP. Constata-se também que não há DCN específicas para a Educação Profissional Técnica de Nível Médio de Enfermagem (BRASIL, 2012a).

Ao planejar o ensino, o professor deve não somente a seleção dos conteúdos, mas, sobretudo, as estratégias de ensino que serão utilizadas em sala de aula (SÁ et al., 2017), para potencialização dos alunos enquanto sujeitos ativos. 
A estratégia de ensino "aula expositiva dialogada" foi escolhida para que a pesquisadora pudesse expor o conteúdo com a participação ativa dos alunos, na tentativa de levá-los ao questionamento, interpretação e discussão com o objeto do estudo a partir do reconhecimento e confronto com a realidade, fazendo com que os mesmos ultrapassem a passividade e imobilidade intelectual (SÁ et al., 2017; ANASTASIOU; ALVES 2004).

Durante a atividade notou-se que os alunos participaram ativamente e fizeram questionamentos. Todavia, esta estratégia também apresenta desvantagens, tais como torna-se necessário ouvir o estudante, buscando conhecer sua realidade e seus conhecimentos prévios (ANASTASIOU; ALVES, 2004), ações que foram realizadas durante a execução da atividade desta pesquisa.

Já o "júri simulado" foi selecionado como um meio de facilitar a articulação entre o conhecimento teórico e a vivência prática, fazendo com que o aluno refletisse sobre sua ação e a tomada de decisão. Por meio do relato verbal dos alunos foi possível perceber que os estudantes participantes gostaram da atividade, se sentiram motivados para aprender e incluídos no processo de formação. O júri simulado é compreendido como uma estratégia dinâmica para estimular a reflexão dialogada, o pensamento crítico e a exposição e o respeito às diferenças e a tomada de posição a partir de argumentos sólidos (SOUZA et al., 2016; ANASTASIOU; ALVES, 2004).

Nesta perspectiva, apreende-se que estas duas atividades proporcionaram espaços para o aluno ressignificasse sua aprendizagem a partir de conhecimentos prévios científicos e não científicos, da mesma forma como ocorre na aprendizagem significativa, que é compreendida como a construção de novas aprendizagens ancoradas em conhecimentos já significativos anteriormente para o aluno (BIANCHESSI; MENDES, 2019; MOREIRA, 1999).

A aprendizagem significativa ocorre quando o aluno utiliza de suas próprias proposições ou conceitos já são preexistentes na sua estrutura cognitiva para dar significado ao novo conteúdo que lhe é disponibilizado, ressignificando-o (BIANCHESSI; MENDES, 2019; MOREIRA, 1999).

Assim, por meio de uma atividade teórica introdutória buscou-se criar um ambiente de aprendizagem adequado para que o aluno pudesse aplicar o conteúdo de comunicação na simulação clínica durante a atividade prática, ou seja, resgatando conteúdo prévio a fim de construir a aprendizagem significativa por meio da assimilação das novas 
experiências/conteúdos com conteúdo preexistente (BIANCHESSI; MENDES, 2019; MOREIRA, 1999).

Apesar de a comunicação ser considerada um conteúdo transversal na formação do profissional de saúde (FRENK et al., 2010; BRASIL, 2001), neste estudo, este tema foi aplicado por meio da simulação clínica em uma atividade única, sem relação direta com os conteúdos que estavam sendo ensinados aos estudantes do curso de auxiliar de enfermagem. Cabe ressaltar também que esta estratégia não é adotada rotineiramente na instituição de ensino. Também se buscou uma estratégia que preparasse o estudante para o primeiro contato com o paciente/família nos estágios em ambiente hospitalar.

A comunicação em saúde deve abranger conhecimentos e relatos de forma prática, pois o processo de comunicação na presença de complicadores, como uso abusivo de jargões técnicos e uso de linguagem inacessível e científica dificulta o entendimento da realização de procedimentos, diagnósticos e adesão de tratamento do paciente tornando-se uma forma inadequada de comunicação com o paciente (BUCKER et al., 2018; CAMPOS et al., 2008).

Apesar da comunicação ser reconhecida como uma ação de alta prioridade para a segurança do paciente (EDWARDS; SIASSAKOS, 2012; FAY-HILLIER; REGAN; GALLAGHER, 2012; ROBSON, 2014), estudos empíricos fornecem evidências de que a falta de comunicação por profissionais da assistência em saúde pode levar ao paciente erros de medicação ou não aderência ao tratamento; mal-entendido; falta de competência em cuidar e diminuição da satisfação do paciente (O’SHEA et al., 2013).

Para que ocorra melhorias na habilidade de comunicação em saúde do estudante de enfermagem, professores devem proporcionar experiências em que se possa praticar e alcançar comportamentos sobre comunicação antes do contato direto com paciente e família (O’SHEA et al., 2013).

No contexto da formação do estudante de enfermagem a simulação clínica pode ser utilizada para treinamento de capacidades técnicas (conhecimento e habilidades) e não técnicas (comunicação, atitude e trabalho em equipe, por exemplo) (KANEKO et al., 2015); melhorar a segurança do cuidado ao paciente (NATIONAL COUNCIL OF STATE BOARDS OF NURSING, 2014; CAMPBELL, 2013; NATIONAL LEAGUE..., 2008) e criar oportunidade de aprendizagem ativa (CAMPBELL, 2013; NATIONAL LEAGUE..., 2008).

A simulação, quando aplicada como uma estratégia auxiliar de ensino inserido no PPP, proporciona oportunidades para a aprendizagem do estudante considerando a prática baseada em evidência (SCALABRINI; FONSECA; BRANDÃO, 2017); estimula o estudante de 
enfermagem para aplicar os conceitos teóricos na vivência prática da simulação (BAMBINI; WASHBURN; PERKINS, 2009; NATIONAL LEAGUE..., 2008); estimula a confiança do aluno (ARTHUR; LEVETT-JONES; KABLE, 2013; CAMPBELL, 2013); o pensamento crítico (NATIONAL COUNCIL OF STATE BOARDS OF NURSING, 2014; CAMPBELL; DALEY, 2013; JEFFRIES, 2005); a tomada de decisão (ARTHUR; LEVETT-JONES; KABLE, 2013); o treino de habilidades práticas (NATIONAL COUNCIL OF STATE BOARDS OF NURSING, 2014; JEFFRIES, 2005); a comunicação (NATIONAL COUNCIL OF STATE BOARDS OF NURSING, 2014; ARTHUR; LEVETT-JONES; KABLE, 2013; CAMPBELL, 2013; CAMPBELL; DALEY, 2013) e a participação ativa do indivíduo com oportunidades para a repetição, feedback, avaliação e reflexão (COGO et al., 2019; QUIRÓS; VARGAS, 2014).

Para que a simulação clínica seja realizada, é necessária a formação dos professores pois, além de a seleção de estratégias adequadas de acordo com os objetivos educacionais, (SÁ et al., 2017) a simulação, trata-se de uma estratégia que demanda clareza conceitual para sua aplicação.

Dessa forma, a formação docente para simulação visa a orientação para o domínio das estratégias, para criação de novos ambientes para aprendizagem e para desenvolvimento da mesma. Para isso, o docente deve ser proativo para o conhecimento das técnicas e criação do desenho e avaliação das práticas simuladas (GOMEZ; VIEIRA; SCALABRINI, 2011).

Segundo o Art. 40 das DCN para a EPTNM, a formação para a docência na EPTNM realiza-se em cursos de graduação e programas de licenciatura ou outras formas, em consonância com a legislação e com normas específicas definidas pelo Conselho Nacional de Educação (BRASIL, 2012a).

No entanto, podemos perceber que a composição de docentes atuantes na EPTNM da escola participante da pesquisa conta em sua maioria, apenas com cursos de graduação, não licenciados em efetivo exercício na profissão docente. Ao exemplo supracitado, em relação aos cursos de graduação em enfermagem, falhas podem ser apontadas na formação dos profissionais enfermeiros licenciados com vistas na atuação nos campos da docência, uma vez que a educação permanece direcionada para atividades assistenciais (CARVALHO et al., 2015; CORREA; SORDI, 2018).

Sobre a infraestrutura para o processo ensino aprendizagem na EPTNM em enfermagem, de acordo com o Catálogo Nacional de Cursos do Ministério da Educação brasileiro (BRASIL, 2016), as escolas técnicas devem oferecer estrutura mínima com espaços 
para biblioteca e videoteca com conteúdo atualizados e específicos da área de formação e laboratórios de informática, enfermagem, anatomia e fisiologia.

Estudo realizado em quatro escolas técnicas demonstrou que muitas delas fazem adaptações em sua infraestrutura, as quais repercutem em dificuldades de acessibilidade, ruídos externos intensos, simbolizando falta de investimentos na infraestrutura. Há dificuldades para aquisição de recursos didáticos imprescindíveis para a formação do técnico de enfermagem, incluindo-se aí questões associadas a simulação em laboratórios (CAMARGO et al., 2016).

Apesar da autoavaliação da satisfação dos alunos participantes da pesquisa ter apresentado médias altas, o resultado da avaliação da habilidade de comunicação demonstrou que os alunos não estavam preparados. Ademais as falas das entrevistas quando colocam a comunicação aplicada no contexto do cuidado tecnicista, repetitivo e apenas informacional reforçam os resultados evidenciados pela HCAT.

De acordo com os dados supracitados, os resultados indicaram a autoconfiança e satisfação positiva para aprendizagem do aluno, porém, os dados da escala HCAT evidenciaram que em onze afirmações as médias para cada uma delas estão abaixo de 2,5, dessa forma, não caracterizando a aprendizagem significativa de fato, ou seja, podemos dizer que o aluno obteve o conteúdo de forma teórica com resgate do mesmo para ancoragem na simulação clínica, porém, não foi aplicado durante a realização da simulação ou com o paciente e família durante o estágio prático pelos alunos.

Finalmente, acredita-se que os resultados das escalas e da entrevista evidenciaram que apesar dos alunos demonstrarem-se satisfeitos com a aprendizagem por meio da simulação, algumas afirmações denotam que eles não têm confiança na sua própria aprendizagem. Tais situações podem expressar as fragilidades históricas da formação na EPTNM tais como: propostas de currículos pedagógicos baseadas em concepções neoliberais, incentivando o indivíduo a buscar seu espaço no mercado de trabalho; a não relevância da necessidade de trabalhadores com formação ético-política devido à grande participação do setor privado no saúde inserida no SUS e EPTNM; a formação técnica consistente e quase sempre centrada na dimensão instrumental; a formação deficitária dos professores atuantes na EPTNM de acordo com os princípios do SUS, entre outros. Tais fragilidades reforçam a formação de profissionais de nível técnico despreparados para lidar com a população brasileira, carentes de competências atitudinais e técnica consistentes, com visão restrita sobre o mundo e a sociedade (CORREA, SORDI, 2018). 
Aparentemente os alunos não estão conseguindo dar significado ao conhecimento novo, alicerçando-o em conhecimento prévio, a medida que mesmo tendo uma atividade de formação a qual associou aula teórica, na qual foi resgatado conhecimento prévio utilizando duas estratégias de ensino diferentes, e a simulação clínica enquanto um recurso ativo para a formação, não conseguiram aplicar na prática durante o estágio, ou aplicaram-no na lógica do cuidado procedimental, repetitivo e informacional.

Embora muitos autores defendam a integração entre conhecimentos formais e conhecimentos tácitos, Kuenzer (2007) afirma que há dificuldade na utilização de conhecimentos prévios dos aprendizes, pois as desigualdades socioeconômicas dificultam o acesso à produção cultural dominante. A escola, nesse caso, é espaço fundamental para permitir o desenvolvimento das competências requeridas para a inclusão social e na vida produtiva.

A aprendizagem quando significativa poderia ajudar o estudante em não garantir a aprendizagem mecânica com relacionabilidade à estrutura cognitiva. Por meio da utilização dos fatores que compõem a teoria da aprendizagem significativa, o indivíduo faz o resgate de uma estrutura cognitiva prévia adequada que vai permitir a aprendizagem, sendo considerada eficaz, porém não instantânea, pois requer intercâmbio de significados (MOREIRA, 1999). 
7. CONCLUSÕES 
Por meio deste estudo foi possível verificar se a simulação clínica de alta fidelidade utilizando atores contribui na satisfação e autoconfiança do estudante de nível técnico de enfermagem, além de avaliar as habilidades de comunicação de estudantes da educação profissional técnica de nível médio em enfermagem e a autoconfiança na aprendizagem e satisfação percebida dos estudantes.

Apesar dos resultados apontarem para a autoconfiança do estudante manter-se em médias que os corroborava como altamente confiantes, por outro lado, os resultados do HCAT mantiveram-se em médias inferiores durante a realização do cenário, e as falas das entrevistas demonstra fragilidade e insegurança na comunicação com o paciente e família.

Constatou-se também que a simulação clínica, quando aplicada de forma isolada na estrutura curricular, não refletiu diretamente na satisfação do estudante e autoconfiança na aprendizagem.

A utilização de uma amostra intencional de conveniência pode não representar a população geral de estudantes de cursos técnicos de enfermagem brasileiros e limita a capacidade de generalização para outros cursos de enfermagem. Escolhemos o local de coleta de dados e a turma de curso no estudo, criando um viés em potencial para garantir que os alunos ainda não tivessem tido contato com a prática clínica. Além disso, o presente trabalho apresentou também a não realização das entrevistas com todos os estudantes da turma devido à ausência no período de estágio.

Fica evidente a necessidade premente de investimento em novas estratégias que atraiam o aluno e resgatem o conhecimento prévio com a associação a novos conhecimentos e garantam a aprendizagem significativa com vistas a formação de técnicos de enfermagem competentes, éticos e munidos de habilidades comunicativas.

A educação em enfermagem para obter qualidade necessita de inovação e responsabilidade, pois está em constante transformação juntamente com as práticas educativas. O estudo contribui com a compreensão de aspectos singulares utilizando estratégias de metodologias ativas considerando a aprendizagem significativa com estudantes do ensino técnico de nível médio em comunicação, um dos eixos mais importantes da assistência em saúde e do cuidado ao paciente. 
REFERÊNCIAS 
ALEXANDER, L. et al. Mental health simulation with student nurses: a qualitative review. Clinical Simulation in Nursing, New, York, v. 14, p. 8-14, jan. 2018. Disponível em: <https://www.sciencedirect.com/science/article/pii/S1876139917301664>. Acesso em: 22 jan. 2019.

ALMEIDA, R. G. S. et al. Validação para a língua portuguesa do Educational Practices Questionnaire (Student Version). Acta Paulista de Enfermagem, São Paulo, v. 29, n. 4, p. 390396, jul./ago. 2016. Disponível em: <http://www.scielo.br/scielo.php?pid=S010321002016000400390\&script=sci_arttext\&tlng=pt>. Acesso em: 31 out. 2017.

ALMEIDA, R. G. S. et al. Validação para a língua portuguesa da escala Student Satisfaction and Self-Confidence in Learning. Revista Latino-Americana de Enfermagem, Ribeirão Preto, v. 23, n. 6, p. 1007-1013, 2015. Disponível em: <http://www.scielo.br/pdf/rlae/v23n6/pt_0104-1169-rlae-2306-01007.pdf>. Acesso em 17 out. 2017.

ANASTASIOU, L. G. C.; ALVES, L. P. Estratégias de ensinagem. 2004. Disponível em: <https://www.ufmt.br/proeg/arquivos/2dc95cd453e52a78a17dcc157f04dbf6.pdf>. Acesso em: 4 maio 2019.

ARTHUR, C.; LEVETT-JONES, T.; KABLE, A. Quality indicators for the design and implementation of simulation experiences: a Delphi study. Nurse Education Today, Edinburgh, v. 33, n. 11, p. 1357-1361, nov. 2013. Disponível em:

<https://www.sciencedirect.com/science/article/pii/S0260691712002511?via\%3Dihub>. Acesso em: 31 out. 2018.

BAMBINI, D.; WASHBURN, J.; PERKINS, R. Outcomes of clinical simulation for novice nursing students: communication, confidence, clinical judgment. Nursing Education

Perspectives, New York, v. 30, n. 2, p.79-82, 2009. Disponível em:

<https://insights.ovid.com/pubmed?pmid=19476069>. Acesso em: 19 jan. 2019.

BARBOSA, I. A. et al. O processo de comunicação na telenfermagem: revisão integrativa. Revista Brasileira de Enfermagem, Brasília, v. 69, n. 4, p.718-725, out./dez. 2016. Disponível em: 〈http://www.scielo.br/pdf/reben/v69n4/0034-7167-reben-69-04-0765.pdf〉. Acesso em: 23 nov. 2017.

BARDIN, L. Análise de conteúdo. Lisboa: Edições 70, 1979.

BIANCHESSI, C.; MENDES, A. A. P. Ensino de história por meio de jogos digitais: relato de aprendizagem significativa com games. Revista Tempos e Espaços em Educação, São Cristóvão, v. 12, n. 29, p. 145-160, abr./maio 2019. Disponível em:

<https://seer.ufs.br/index.php/revtee/article/view/9660/pdf>. Acesso em: 10 maio 2019.

BRANDÃO, C. F. S.; COLLARES, C. F.; MARIN, H. F. A simulação realística como ferramenta educacional para estudantes de medicina. Revista Scientia Medica, Porto Alegre, v. 24, n. 2, p. 187-192, abr./jun. 2014. Disponível em: 
<http://revistaseletronicas.pucrs.br/ojs/index.php/scientiamedica/article/view/16189/11485>. Acesso em: 6 ago. 2017.

BRASIL. Ministério da Educação. Catálogo nacional de cursos técnicos. 3. ed. Brasília, DF: MEC, 2016. Disponível em:

$<$ http://portal.mec.gov.br/index.php?option=com_docman\&view=download\&alias=77451-cnct3a-edicao-pdf-1\&category_slug=novembro-2017-pdf\&Itemid=30192>. Acesso em: 2 mar. 2019.

BRASIL. Ministério da Educação. Conselho Nacional de Educação. Câmara de Educação Superior. Resolução CNE/CES n 3, de 7 de novembro de 2001. Institui as diretrizes curriculares nacionais do curso de graduação em enfermagem. Diário Oficial [da] República Federativa do Brasil, Brasília, DF, 9 nov. 2001. Disponível em:

<http://portal.mec.gov.br/cne/arquivos/pdf/CES03.pdf>. Acesso em: 26 mar. 2018.

BRASIL. Ministério da Educação. Conselho Nacional de Educação. Resolução nº 6, de 20 de setembro de 2012. Define diretrizes curriculares nacionais para a educação profissional técnica de nível médio. Diário Oficial da União, Brasília, DF, 21 de setembro de 2012a, Seção 1, p. 22. Disponível em:

<http://portal.mec.gov.br/index.php?option=com_docman\&view=download\&alias=11663-rceb006-12pdf\&category_slug=setembro-2012-pdf\&Itemid=30192>. Acesso em: 2 jan. 2018.

BRASIL. Ministério da Saúde. Conselho Nacional de Saúde. Resolução no 466, de 12 de dezembro de 2012b. Aprova normas regulamentadoras de pesquisas envolvendo seres humanos. Disponível em: <http://bvsms.saude.gov.br/bvs/saudelegis/cns/2013/res0466_12_12_2012.html>. Acesso em: 21 set. 2017.

BRASIL. Ministério da Saúde. Gabinete do Ministro. Portaria no 83, de 10 de janeiro de 2018. Institui o Programa de Formação Técnica para Agentes de Saúde - PROFAGS, para oferta de curso de formação técnica em enfermagem para agentes comunitários de saúde - ACS e agentes de combates às endemias - ACE no âmbito do SUS, para o biênio de 2018-2019. Diário Oficial da União, Brasília, DF, 12 de janeiro de 2018a. Disponível em:

<http://bvsms.saude.gov.br/bvs/saudelegis/gm/2018/prt0083_12_01_2018.html>. Acesso em: 4 fev. 2019.

BRASIL. Ministério da Saúde. Ministério da Saúde formará 250 mil agentes em técnico em enfermagem. Brasília, DF, 2018b. Disponível em: <http://portalms.saude.gov.br/noticias/agenciasaude/42358-ministerio-da-saude-formara-250-mil-agentes-em-tecnico-em-enfermagem>. Acesso em: 29 abr. 2018

BRASIL. Ministério da Saúde. Rede de escolas técnicas do SUS (RET-SUS). Brasília, DF, 2017. Disponível em: <http://www.saude.gov.br/trabalho-educacao-e-qualificacao/gestao-daeducacao/formacao-tecnica/rede-de-escolas-tecnicas-do-sus-ret-sus>. Acesso em: 28 mar. 2019. 
BRASIL. Presidência da República. Casa Civil. Lei no 9.394, de 20 de dezembro de 1996. Estabelece as diretrizes e bases da educação nacional. Disponível em:

<http://www.planalto.gov.br/ccivil_03/leis/L9394.htm>. Acesso em: 30 nov. 2017.

BRASIL. Presidência da República. Casa Civil. Lei no 7.498, de 25 de junho de 1986. Dispõe sobre a regulamentação do exercício da enfermagem, e dá outras providências. em: <http://www.planalto.gov.br/ccivil_03/LEIS/L7498.htm>. Acesso em: 18 fev. 2019.

BUCKER, L. C. G. et al. Comunicação acessível na relação médico-paciente durante a anamnese. Revista Interdisciplinar do Pensamento Científico, Itaperuna, v. 4, n. 1, 2018. Disponível em: <http://reinpec.srvroot.com:8686/reinpec/index.php/reinpec/article/view/368>. Acesso em: 22 mar. 2019.

CAMACHO, H. M. Simulación cibernética en las ciéncias de la salud. Recuento histórico em el Mundo y Colombia y su impacto en la educación. 2 ed. Bogotá: Kimpres, 2010.

CAMARGO, R. A. A. et al. Ambiente de aprendizagem: o espaço escolar da educação profissional técnica de nível médio em enfermagem. Revista Enfermagem UERJ, Rio de Janeiro, v. 24, n. 3, p.1-7, 2016. Disponível em: <https://www.epublicacoes.uerj.br/index.php/enfermagemuerj/article/view/10543/20385>. Acesso em: 23 mar. 2019.

CAMPBELL, S. H. Role-playing: an underutilized tool for teaching students to think, act, and reflect like a nurse. Clinical Simulation in Nursing, New York, v. 8, n. 7, p. 261-262, set. 2012. Disponível em: <https://www.nursingsimulation.org/article/S1876-1399(11)00057-0/fulltext >. Acesso em: 22 mai. 2018.

CAMPBELL, S. H. Using simulation cases in an undergraduate nursing program: bridging the theory practice gap. International Journal of Case Method Research \& Application, SaintPetersburg, v. 25, n. 2, p. 80-92, 2013. Available from:

<http://www.wacra.org/PublicDomain/IJCRA\%20xxv_ii_pg80-92\%20Campbell.pdf >. Acesso em: 14 mar. 2018.

CAMPBELL, S. H.; DALEY, K. Introduction. In: CAMPBELL, S. H.; DALEY, K. Simulation scenarios for nurse educators: making it real. 2. ed. New York: Springer, 2013.

CAMPOS, A. C. S. et al. Comunicação: instrumento básico da enfermagem para cuidar da mãe do neonato sob fototerapia. Rev Rene, Fortaleza, v. 9, n. 4, p. 24-32, 2008. Disponível em: <https://www.redalyc.org/html/3240/324027964003/>. Acesso em: 18 nov. 2017.

CARDOSO, M. L. M. et al. A política nacional de educação permanente em saúde nas escolas de saúde pública: reflexões a partir da prática. Revista Ciência \& Saúde Coletiva, Rio de Janeiro, v. 22, n. 5, p. 1489-1500, 2017. Disponível em: <http://www.scielo.br/pdf/csc/v22n5/1413-8123-csc-2205-1489.pdf >. Acesso em: 22 ago. 2017. 
CARVALHO, D. P. S. R. P. et al. Teoria da aprendizagem significativa como proposta para inovação no ensino de enfermagem: experiência dos estudantes. Revista de Enfermagem da UFSM, Santa Maria, v. 5, n. 1, p. 186-192, jan./mar. 2015. Disponível em: <https://periodicos.ufsm.br/reufsm/article/view/13210/pdf>. Acesso em: 5 fev. 2019.

CENTRO ESTADUAL DE EDUCAÇÃO TECNOLÓGICA PAULA SOUZA. Plano de curso para: habilitação profissional técnica de nível médio de técnico em enfermagem e qualificação técnica de nível médio de auxiliar de enfermagem. São Paulo, 2012. Disponível em: <http://etecdrc.com.br/wp-content/uploads/2014/07/Enfermagem.pdf>. Acesso em: 1 mar. 2019.

COGO, A. L. P. et al. Construção e desenvolvimento de cenários de simulação realística sobre a administração segura de medicamentos. Revista Gaúcha de Enfermagem, Porto Alegre, v. 40, 2019. Disponível em: <http://www.scielo.br/scielo.php?script=sci_arttext\&pid=S198314472019000200801\&lng=pt\&nrm=iso\&tlng=pt>. Acesso em: 1 fev. 2019.

COLONI, C. S. M. et al. Prática pedagógica na educação profissional de nível médio em enfermagem. Cogitare Enfermagem, Curitiba, v. 21, n. 11, p. 1-9, jan./mar. 2016. Disponível em: <https://revistas.ufpr.br/cogitare/article/view/42026/27505>. Acesso em: 19 jan. 2019.

CONSELHO FEDERAL DE ENFERMAGEM. Enfermagem em números. 2018. Disponível em: <http://www.cofen.gov.br/enfermagem-em-numeros>. Acesso em: 24 nov. 2018.

CORIOLANO-MARINUS, M. W. L. et al. Comunicação nas práticas em saúde: revisão integrativa da literatura. Saúde e Sociedade, São Paulo, v. 23, n. 4, p. 1356-1369, out./dez. 2014. Disponível em: <http://www.scielo.br/scielo.php?script=sci_arttext\&pid=S0104-12902014000401356> . Acesso em: 2 jan. 2018.

CORREA, A. K.; SORDI, M. R. L. Educação profissional técnica de nível médio no sistema único de saúde e a política de formação de professores. Texto e Contexto Enfermagem, Florianópolis, v. 27, n. 1, p. 1-8, 2018. Disponível em: <http://www.scielo.br/pdf/tce/v27n1/0104-0707-tce-27-01e2100016.pdf>. Acesso em: 24 jun. 2019.

COSTA, R. R. O. et al. O uso da simulação no contexto da educação e formação em saúde e enfermagem: uma reflexão acadêmica. Revista Espaço para a Saúde, Londrina, v. 16, n. 1, p. 59-65, jan./mar. 2015. Disponível em:

http://espacoparasaude.fpp.edu.br/index.php/espacosaude/article/view/418>. Acesso em: 24 set. 2017

CRESWELL, J. W.; CLARK, V. L. P. Pesquisa de métodos mistos. 2. ed. São Paulo: Penso, 2015. (Série métodos de pesquisa).

EDWARDS, S.; SIASSAKOS, D. Training teams and leaders to reduce resuscitation errors and improve patient outcome. Resuscitation, London, v. 83, n. 1, p. 13-15, 2012. Disponível em: <https://www.sciencedirect.com/science/article/pii/S0300957211006149?via\%3Dihub>. Acesso em: 28 dez. 2017. 
FABRI, R. P. et al. Construção de um roteiro teórico-prático para simulação clínica. Revista da Escola de Enfermagem da USP, São Paulo, v. 51, p. 1-7, 2017. Disponível em:

<http://www.scielo.br/pdf/reeusp/v51/pt_1980-220X-reeusp-51-e03218.pdf〉. Acesso em: 29 nov. 2017.

FAY-HILlIER, T. M.; REGAN, R. V.; GALLAGHER, G. M. Communication and patient safety in simulation for mental health nursing education. Issues in Mental Health Nursing, London, v. 33, n. 11, p. 718-726, 2012. Disponível em:

<https://www.tandfonline.com/doi/full/10.3109/01612840.2012.709585>. Acesso em: 2 jan. 2018.

FERNANDES, J. D.; REBOUÇAS, L. C. Uma década de diretrizes curriculares nacionais para a graduação em enfermagem: avanços e desafios. Revista Brasileira de Enfermagem, Brasília, DF, v. 66, p. 95-101, 2013. Disponível em:

<http://www.scielo.br/pdf/reben/v66nspe/v66nspea13.pdf>. Acesso em: 15 mar. 2019.

FREITAG, R. M. K. Amostras sociolinguísticas: probabilísticas ou por conveniência? Revista de Estudos da Linguagem, Belo Horizonte, v. 26, n. 2, p. 667-686, 2018. Disponível em:

<http://www.periodicos.letras.ufmg.br/index.php/relin/article/view/12412>. Acesso em 4 fev. 2019.

FRENK, J. et al. Health professionals for a new century: transforming education to strengthen health system in an interdependent world. The Lancet, London, v. 376, p. 1923-1958, 2010. The Lancet Commissions. Disponível em: <https://www.thelancet.com/journals/lancet/article/PIIS01406736(10)61854-5/fulltext>. Acesso em: 21 maio 2019.

GÓES, F. S. N. et al. Necessidades de aprendizagem de alunos da educação profissional de nível técnico em enfermagem. Revista Brasileira de Enfermagem, Brasília, DF, v. 68, n. 1, p. 20-25, jan./fev. 2015. Disponível em: <http://www.scielo.br/pdf/reben/v68n1/0034-7167-reben-68-010020.pdf >. Acesso em: 2 jan. 2018. ]

GÓES, F. S. N. et al. Simulação com pacientes padronizados: habilidades de comunicação em saúde do estudante de enfermagem. Rev Rene, Fortaleza, v. 18 n. 3 p. 383-389, 2017. Disponível em: <http://www.periodicos.ufc.br/rene/article/view/20067>. Acesso em: 2 jan. 2018.

GOMES, A. P. et al. A educação médica entre mapas e âncoras: a aprendizagem significativa de David Ausubel, em busca da Arca Perdida. Revista Brasileira de Educação Médica, Rio de Janeiro, v. 29, n. 1, p. 105-111, 2008. Disponível em: <http://www.scielo.br/scielo.php?pid=S010055022008000100014\&script=sci_abstract\&tlng=es>. Acesso em: 11 fev. 2019.

GOMEZ, M. V.; VIEIRA, J. E.; SCALABRINI NETO, A. Análise do perfil de professores da área da saúde que usam a simulação como estratégia didática. Revista Brasileira de Educação Medica, Rio de Janeiro, v. 35, n. 2, p. 157-162, abr./jun. 2011. Disponível em: $<$ http://www.scielo.br/scielo.php?pid=S0100-55022011000200003\&script=sci_abstract\&tlng=pt >. Acesso em: 4 maio 2019. 
GONZALES, E. G.; ROSA, P. R. S. Aprendizagem significativa de conceitos de circuitos elétricos utilizando um ambiente virtual de ensino por alunos da educação de jovens e adultos. Investigações em Ensino de Ciências, Porto Alegre, v. 19, n. 2, p. 477-504, 2014. Disponível em: 〈https://www.if.ufrgs.br/cref/ojs/index.php/ienci/article/view/91>. Acesso em 4 fev. 2019.

HALLIN, K. et al. High-fidelity simulation: assessment of student nurses' team achievements of clinical judgment. Nurse Education in Practice, Edinburgh, v. 19, p. 12-18, jul. 2016. Available from: <https://www.sciencedirect.com/science/article/abs/pii/S1471595316300129 >. Acesso em: 1 mar. 2019.

HEALE, R.; BUCKLEY, C. R. An international perspective of advanced practice nursing regulation. International Nursing Review, Oxford, v. 62, p. 421-429, 2015. Disponível em: <https://onlinelibrary.wiley.com/doi/pdf/10.1111/inr.12193>. Acesso em: 20 mar. 2019.

IGNACIO, J. et al. Comparison of standardized patients with high-fidelity simulators for managing stress and improving performance in clinical deterioration: a mixed methods study. Nurse Education Today, Edinburgh, v. 35, n. 12, p.1161-1168, maio 2015. Disponível em: <https://www.sciencedirect.com/science/article/pii/S0260691715002269?via\%3Dihub>. Acesso em: 22 nov. 2017.

JEFFRIES, P. R. A framework for designing, implementing, and evaluating simulations used as teaching strategies in nursing. Nursing Education Perspectives, New York, v. 26, n. 2, p. 96103, mar/abr. 2005.

JEFFRIES, P. Simulation in nursing education: from conceptualization to evaluation. New York: National League for Nursing, 2007.

KANEKO, R. M. U. et al. Simulação in situ, uma metodologia de treinamento multidisciplinar para identificar oportunidades de melhoria na segurança do paciente em uma unidade de alto risco. Revista Brasileira de Educação Médica, Brasília, DF, v. 39, n. 2, p. 286-293, 2015. Disponível em: 〈http://www.scielo.br/scielo.php?pid=S0100-55022015000200286\&script=sci_abstract\&tlng=pt>. Acesso em: 13 out. 2018.

KUENZER, A. Z. Da dualidade assumida à dualidade negada: o discurso da flexibilização justifica a inclusão excludente. Educação \& Sociedade, Campinas, v. 28, n .100, p. 1153-1178, out. 2007. Disponível em: 〈http://www.redalyc.org/pdf/873/87313704024.pdf>. Acesso em: 10 jun. 2019.

LAZZARI, D. D. et al. Estratégias de ensino do cuidado em enfermagem: um olhar sobre as tendências pedagógicas. Revista Gaúcha de Enfermagem, Porto Alegre, v. 32, n. 4, p. 688-694, dez. 2011. Disponível em: 〈http://seer.ufrgs.br/RevistaGauchadeEnfermagem/article/view/16751〉. Acesso em: 3 jan. 2018. 
LEIGH, G. T. High-fidelity patient simulation and nursing students self-efficacy: a review of the literature. International Journal of Nursing Education Scholarship, Berkeley, v. 5, n. 1, p. 116, 2008.

MAKUCH, D. M. V; ZAGONEL, I. P. S. Abordagem pedagógica na implementação de programas curriculares na formação do enfermeiro. Escola Anna Nery Revista de Enfermagem, Rio de Janeiro, v. 21, n. 4, p. 1-9, 2017. Disponível em:

<https://www.redalyc.org/pdf/1277/127752022016.pdf >. Acesso em: 22 abr. 2019.

MARIN, M. J. S. et al. Estudantes de curso técnico em enfermagem e sua motivação para o trabalho em enfermagem. Revista Eletrônica de Enfermagem, Goiânia, v. 16, n. 2, p. 401-407, abr./jun. 2014. Disponível em: <https://www.fen.ufg.br/revista/v16/n2/pdf/v16n2a17.pdf >. Acesso em: 12 nov. 2017.

MARK, B. A.; SALYER, J.; WAN, T. T. H. Professional nursing practice: impact on organizational and patient outcomes. Journal of Nursing Administration, Philadelphia, v. 33, n. 4, p. 224-234, abr. 2003. Disponivel em :

<https://pdfs.semanticscholar.org/47d9/130e4dd456e07b7784df97e6767fe5ea1b2e.pdf>. Acesso em: 22 maio 2018.

MATO GROSSO DO SUL (Estado). Conselho Estadual da Educação. Regimento da Escola Técnica do SUS "Professora Ena de Araújo Galvão". Campo Grande, 2008. Disponível em: $<$ http://www.etsus.ms.gov.br/wpcontent/uploads/sites/64/2015/04/Regimento_Escolar_2008_6out2008.pdf>. Acesso em 21 fev. 2019.

MAZZO, A. et al. Simulação e a videoconferência no ensino de enfermagem. Revista de Graduação USP, São Paulo, v. 2, n. 2, jun. 2017. Disponível em:

<http://www.revistas.usp.br/gradmais/article/view/123765/130064>. Acesso em: 17 dez. 2017.

MEIRA, M. D. D.; KURCGANT, P. Educação em enfermagem: avaliação da formação por egressos, empregadores e docentes. Revista Brasileira de Enfermagem, Brasília, DF, v. 69, n. 1, p. 10-15, jan./fev. 2016. Disponível em:

<http://www.scielo.br/scielo.php?script=sci_arttext\&pid=S0034-71672016000100016>. Acesso em: 28 ago. 2017.

MOREIRA, A. M. A teoria da aprendizagem significativa de Ausubel. In: MOREIRA, A. M. Teorias de aprendizagem. São Paulo: EPU, 1999.

NATIONAL COUNCIL OF STATE BOARDS OF NURSING. The NCSBN national simulation study: a longitudinal, randomized, controlled study replacing clinical hours with simulation in prelicensure nursing education. Journal of Nursing Regulation, Chicago, v. 5, n. 2, p. S3-S40, jul. 2014. Supplement. Disponível em:

<https://www.journalofnursingregulation.com/article/S2155-8256(15)30062-4/pdf>. Acesso em: 01 abr. 2018. 
NATIONAL LEAGUE for nursing research grants program advances the science of nursing education: NLM 2008 research priorities: innovations in teaching in clinical settings, evaluation of clinical performance, and creating reform in nursing education. Washington, DC: NLM, 2008. Disponível em: <http://www.nln.org/newsroom/news-releases/news-release/2008/01/18/nationalleague-for-nursing-research-grants-program-advances-the-science-of-nursing-education-201>. Acesso em: 13 nov. 2018.

NEGRI, E. C. et al. Simulação clínica com dramatização: ganhos percebidos por estudantes e profissionais de saúde. Revista Latino-Americana de Enfermagem, Ribeirão Preto, v. 25, ago. 2017. Disponível em: <http://www.scielo.br/scielo.php?pid=S0104-

11692017000100604\&script=sci_arttext\&tlng=pt>. Acesso em: 22 nov. 2017.

OLIVEIRA, A. et al. Desafios do trabalho de conclusão de curso na formação do técnico de enfermagem. Revista Brasileira de Enfermagem, Brasília, DF, v. 70, n. 6, p. 1212-1219, dez. 2017. Disponível em: http://www.scielo.br/pdf/reben/v70n6/pt_0034-7167-reben-70-061212.pdf. Acesso em: 9 jun. 2018.

OLIVEIRA, L. B. S. et al. Standardized patient simulation model focused on communication: senior undergraduate nursing student satisfaction. In: MARGARET SCOTT WRIGHT RESEARCH AND INNOVATION DAY AND CANADIAN NURSING STUDENTS' ASSOCIATION WESTERN/PRAIRIE REGIONAL CONFERENCE, 30., 2016, Edmonton. Oral Abstract Listing. Edmonton: UofA, 2016. p. 17, v. 1.

OLIVEIRA, S. N. Simulação clínica com participação de atores no ensino da consulta de enfermagem: uma pesquisa-ação. 2014. Dissertação (Mestrado) - Centro de Ciências da Saúde, Universidade Federal de Santa Catarina, Florianópolis, 2014. Disponível em:

$<$ https://repositorio.ufsc.br/xmlui/bitstream/handle/123456789/123331/325335.pdf?sequence=1\&i sAllowed=y>. Acesso em: 14 jun. 2018.

OLIVEIRA, S. N. et al. Da teoria à prática, operacionalizando a simulação clínica no ensino de Enfermagem. Revista Brasileira de Enfermagem, Brasília, DF, v. 71, n. 4, p. 1791-1798, 2018. Disponível em: 〈http://www.scielo.br/pdf/reben/v71s4/pt_0034-7167-reben-71-s4-1791.pdf〉. Acesso em: 4 mar. 2019.

\section{ORGANIZAÇÃO PAN-AMERICANA DE SAÚDE. Oficina de formação de competência e} simulação. Brasília, DF: OPAS, 2015. Disponível em:

<https://www.paho.org/bra/index.php?option=com_content\&view=article\&id=4803: oficina-de-formacaode-competencia-e-simulacao\&Itemid=844> . Acesso em: 28 fev. 2019.

O'SHEA, E. R. et al. A descriptive analysis of nursing student communication behaviors. Clinical Simulation in Nursing, New York, v. 9, n. 1, p. 5-12, jan. 2013. Disponível em: https://www.nursingsimulation.org/article/S1876-1399(11)00100-9/fulltext. Acesso em: 12 maio 2019. 
PARKER, J. M.; HILL, M. N. A review of advanced practice nursing in the United States, Canada, Australia and Hong Kong Special Administrative Region (SAR), China. International Journal of Nursing Sciences, Singapore, v. 4, n. 2, p. 196-204, abr. 2017. Disponível em: <https://www.sciencedirect.com/science/article/pii/S2352013216301910>. Acesso em: 22 mar. 19.

PELIZZARI, A. et al. Teoria da aprendizagem significativa segundo Ausubel. Revista Psicologia, Educação e Cultura, Vila Nova de Gaia, v. 2, n. 1, p. 37-42, 2002. Disponível em: <http://portaldoprofessor.mec.gov.br/storage/materiais/0000012381.pdf>. Acesso em: 11 fev. 2019.

QUIRÓS, S. M.; VARGAS, M. A. O. Simulação clínica: uma estratégia que articula práticas de ensino e pesquisa em enfermagem. Revista Texto \& Contexto Enfermagem, Florianópolis, v. 23, n. 4, p. 813-814, out./dez. 2014. Disponível em: <http://www.scielo.br/pdf/tce/v23n4/pt_01040707-tce-23-04-00815.pdf> Acesso em: 3 de ago. 2017

REIS, N. B. C. et al. Adaptação cultural da ferramenta de avaliação de comunicação em saúde (HCAT) para a língua portuguesa, Brasil. Revista Eletrônica de Comunicação Informação \& Inovação em Saúde, Rio de Janeiro, v. 12 n. 4, p. 444-455, out./dez. 2018. Disponível em: <https://www.reciis.icict.fiocruz.br/index.php/reciis/article/view/1501>. Acesso em: 7 fev. 2019.

RIBEIRO, G.; PIRES, D. E. P.; FLÔR, R. C. Concepção de biossegurança de docentes do ensino técnico de enfermagem em um estado do sul do Brasil. Trabalho, Educação e Saúde, Rio de Janeiro, v. 13, n. 3, p. 721-737, 2015. Disponível em: <http://www.scielo.br/pdf/tes/v13n3/1981-7746tes-13-03-0721.pdf>. Acesso em: 16 nov. 2017.

RIBEIRO, L. O. M.; RIBEIRO, W. O. Espaço vivido e aprendizagem significativa: o educando com deficiência visual nos anos iniciais do ensino fundamental. Revista Educação, Artes e Inclusão, Florianópolis, v. 14, n. 4, p. 57-77, 2018. Disponível em:

<http://www.revistas.udesc.br/index.php/arteinclusao/article/view/11578>. Acesso em: 11 fev. 2019.

ROBSON, W. Eliminating avoidable harm: time for patient safety to play a bigger part in professional education and practice. Nurse Education Today, Edinburgh, v. 34, n. 5, p. e1-2, 2014. Disponível em:

<https://www.sciencedirect.com/science/article/pii/S0260691712001918?via\%3Dihub>. Acesso em: 2 jan. 2018.

SÁ, E. F et al. As aulas de graduação em uma universidade pública federal: planejamento, estratégias didáticas e engajamento dos estudantes. Revista Brasileira de Educação, Rio de Janeiro, v. 22, n. 70, jul./set. 2017. Disponível em: <http://www.scielo.br/scielo.php?pid=S141324782017000300625\&script=sci_abstract\&tlng=pt>. Acesso em: 3 mar. 2019.

SCALABRINI NETO, A.; FONSECA, A.; BRANDÃO, C. F. S. Simulação realística e habilidades na saúde. Rio de Janeiro: Atheneu, 2017. 
SERVIÇO NACIONAL DE APRENDIZAGEM COMERCIAL. Plano de curso de habilitação técnica de nível médio de enfermagem. São Paulo: SENAC, 2006. Disponível em: <https://www.sp.senac.br/downloads/107_enfermagem.pdf>. Acesso em: 11 fev. 2019.

SILVA, T. S. G.; ZARA, R. A. As ciências da natureza no currículo amop e sua relação com a teoria da aprendizagem significativa. Revista Valore, Volta Redonda, v. 3, p. 96-106, 2018. Disponível em: <https://revistavalore.emnuvens.com.br/valore/article/view/139>. Acesso em: $11 \mathrm{fev}$. 2019.

SIRC Glossary. Washington, DC: NLM: SIRC, 2016. Disponível em: <https://sirc.nln.org/mod/glossary/view.php?id=183>. Acesso em: 18 ago. 2017.

SOUSA, A. T. O. et al. A utilização da teoria da aprendizagem significativa no ensino da Enfermagem. Revista Brasileira de Enfermagem, Brasília, DF, v. 68, n. 4, p. 713-722, ago. 2015. Disponível em: 〈http://www.scielo.br/pdf/reben/v68n4/0034-7167-reben-68-04-0713.pdf >. Acesso em: 22 nov. 2017.

SOUSA, M. N. C. et al. Conhecimento de discentes sobre metodologia ativa na construção do processo de ensino aprendizagem inovador. Revista Interdisciplinar Encontro das Ciências, Icó, v. 1, n. 1, p. 61-74, jan./abr. 2018. Disponível em:

<http://www.fvs.edu.br/riec/index.php/riec/article/view/7/5>. Acesso em: 17 jan. 2019.

SOUZA, C. O. et al. Júri simulado: estratégia a contribuir para a construção do conhecimento sobre SUS. Revista Saúde e Desenvolvimento, Curitiba, v. 10, n. 5, p. 101-109, 2016.

Disponível em:

<https://www.uninter.com/revistasaude/index.php/saudeDesenvolvimento/article/view/530/348>. Acesso em: 6 maio 2019.

TAVARES, M. F. L. et al. A promoção da saúde no ensino profissional: desafios na saúde e a necessidade de alcançar outros setores. Revista Ciência \& Saúde Coletiva, Rio de Janeiro, v. 21, n. 6, p. 1799-1808, jun. 2016. Disponível em: 〈http://www.redalyc.org/pdf/630/63046187013.pdf〉. Acesso em: 15 set. 2017.

TEIXEIRA, I. N. D.O.; FELIX, J. V. C. Simulação como estratégia de ensino em enfermagem: revisão de literatura. Interface: comunicação, saúde e educação, Botucatu, v. 15, n. 39, p. 11731184, 2011. Disponível em: <http://www.scielo.br/scielo.php?pid=S141432832011005000032\&script=sci_abstract\&tlng=es >. Acesso em: 27 out. 2017.

TELES, A. C. S. A formação dos licenciados em enfermagem: foco no Sistema Único de Saúde? 2014. Dissertação (Mestrado) - Escola de Enfermagem de Ribeirão Preto, Universidade de São Paulo, Ribeirão Preto, 2014. Disponível em: <http://www.teses.usp.br/teses/disponiveis/22/22132/tde-29052015-104424/pt-br.php>. Acesso em: 6 jan. 2018. 
WINTERS, J. R. F.; PRADO, M. L.; HEIDEMANN, I. T. S. B. A formação em enfermagem orientada aos princípios do Sistema Único de Saúde: percepção dos formandos. Revista Escola Anna Nery, Rio de Janeiro, v. 20, n. 2, p. 248-253, abr./jun. 2016. Disponível em:

<http://www.scielo.br/pdf/ean/v20n2/1414-8145-ean-20-02-0248.pdf >. Acesso em: 3 jan. 2018.

XIMENES NETO, F. R. G. et al. Necessidades de qualificação, dificuldades e facilidades dos técnicos de enfermagem na estratégia saúde da família. Sanare: revista de políticas públicas, Sobral, v. 15, n. 1, p. 47-54, jan./jun. 2016. Disponível em:

<https://sanare.emnuvens.com.br/sanare/article/view/927>. Acesso em: 1 fev. 2019. 
APÊNDICE A - Questionário de caracterização dos participantes da pesquisa

NOME: Nome Social:

1- GÊNERO:

( ) $\mathrm{M}(\mathrm{)} \mathrm{F}$

2- GRAU DE ESCOLARIDADE:

( ) Ensino Fundamental Incompleto ( ) Ensino Fundamental Completo ( ) Ensino Médio Incompleto

( ) Ensino Médio Completo ( ) Ensino Superior Incompleto ( ) Ensino Superior Completo

3- IDADE: anos

4- ESTADO CIVIL:
( ) Solteiro (a)
( ) Casado (a)
( ) Divorciado (a)
( ) Viúvo (a)

5- VOCÊ SE CONSIDERA? (Cor/Etnia):
( ) Branco (a)
( ) Negro (a)
( ) Pardo (a)
( ) Amarelo (a)
( ) Indígena

6- VOCÊ RESIDE EM:
( ) Sertãozinho
( ) Ribeirão Preto
( ) Barrinha
( ) Cruz das Posses
( ) Outro:

\section{7- JÁ PARTICIPOU DE ALGUMA ATIVIDADE EDUCATIVA EM SEU CURSO QUE NÃO SEJA OBRIGATÓRIA?}
( ) $\operatorname{Sim}$
( ) Não
SE SIM, QUAL?

\section{8- JÁ OUVIU FALAR EM SIMULAÇÃO CLÍNICA?}

( ) Sim ( ) Não

9- JÁ CURSOU ALGUM ESTÁGIO NA ÁREA DA ENFERMAGEM?
( ) Sim
( ) Não

10- JÁ OBTEVE DIFICULDADES DE COMUNICAÇÃO COM PACIENTE E/OU FAMÍlIA NO ESTÁGIO?
( ) Sim
( ) Não

11- Qual o setor que deseja trabalhar quando se formar?
( ) Administrativo ( ) Enfermaria Clínica ( ) Enfermaria Cirúrgica ( ) UTI Adulto
( ) UTI Neonatal/Pediátrica ( ) Central de Materiais ( ) Centro Cirúrgico ( )
Unidade de Emergência ( ) Pediatria ( ) Maternidade ( )
Outros: 


\section{APÊNDICE B - Plano de Aula em Comunicação em Saúde}

\section{Dados de Identificação}

Escola: Colégio Tecno-Sert

Turma: Auxiliar de enfermagem

\section{Tema: Comunicação em enfermagem com paciente/família}

\section{Objetivos}

a. Geral: Compreender o processo de comunicação em enfermagem como parte da assistência de saúde ao paciente/família em situação de hospitalização.

\section{b. Específicos:}

1. Entender o conceito de comunicação e os tipos de comunicação existentes;

2. Certificar-se da importância e relevância da comunicação para a prática profissional da enfermagem;

3. Reconhecer iatrogenias relacionadas com a ausência de comunicação efetiva em enfermagem;

4. Aprender sobre técnicas utilizadas em comunicação com paciente/família hospitalizados;

\section{Conteúdos}

Exemplos de má comunicação; definição de comunicação; definição de comunicação verbal e não verbal; importância da utilização da comunicação com pacientes e família hospitalizados; estratégias de comunicação; escuta ativa; a comunicação como segurança do paciente; júri simulado utilizando exemplo de comunicação ineficaz entre equipe de enfermagem.

\section{Metodologia}

Aula expositiva-dialogada. A aula será realizada em sala com os alunos, após a aula expositiva será apresentado o caso a ser trabalhado no júri simulado. A aula expositiva contará com uma proposta de duração entre 1 h00 e 1h30. O júri simulado, por sua vez, será apresentado em 15', divisão da turma 5', estudo do caso e apresentação da promotoria e defesa $40^{\prime}$. Após a realização do exposto acima, será realizado feedback verbal como forma de avaliação dos alunos sobre a estratégia utilizada em 5'.

\section{Recursos Didáticos}

Computador, Monitor, Pendrive; Papel; Caneta; Datashow;

\section{Avaliação}

Avaliação por meio de relatos verbais sobre conteúdo.

\section{Bibliografia}

BROCA, P. V.; FERREIRA, M. A. Equipe de enfermagem e comunicação: contribuições para o cuidado de enfermagem. Revista Brasileira de Enfermagem, 
Brasília, v. 65, n. 1, p. 97-103, jan./fev. 2012. Disponível em: <http://www.scielo.br/pdf/reben/v65n1/14.pdf >. Acesso em: 12 jun. 2018.

MASSOCO, E. C. P.; MELLEIRO, M. M. Comunicação e segurança do paciente: percepção dos profissionais de enfermagem de um hospital de ensino. Revista Mineira de Enfermagem, Belo Horizonte, v. 19, n. 2, p. 192-195, abr.jun. 2015. Disponível em: <http://www.reme.org.br/artigo/detalhes/1014 >. Acesso em: 12 jun. 2018.

SILVA, L. M. G. et al. Comunicação não-verbal: reflexões acerca da linguagem corporal. Revista Latino-Americana de Enfermagem, Ribeirão Preto, v. 8, n. 4, p. 52-58, ago. 2000. Disponível em: <http://www.scielo.br/pdf/rlae/v8n4/12384>.

SILVA, M. J .P.; ARAÚJO, M. M. T. Estratégias de comunicação utilizadas por profissionais de saúde na atenção à pacientes sob cuidados paliativos. Revista da Escola de Enfermagem da USP, São Paulo, v. 46, n. 3, p. 626-632, 2012. Disponível em: 〈http://www.scielo.br/pdf/reeusp/v46n3/14.pdf >. Acesso em: 14 jun. 2018.

ZINN, G. R.; SILVA, M. J. P.; TELLES, S. C. R. Comunicar-se com o paciente sedado: vivência de quem cuida. Revista Latino-Americana de Enfermagem, Ribeirão Preto, v. 11, n. 3, p. 326-332, maio/jun. 2003. Disponível em: <http://www.scielo.br/pdf/rlae/v11n3/16542.pdf>. Acesso em: 15 jun. 2018. 
ANEXO A - Autorização Comitê de Ética

\section{USP - ESCOLA DE \\ ENFERMAGEM DE RIBEIRÃO \\ PRETO DA USP}

\section{PARECER CONSUBSTANCIADO DO CEP}

\section{DADOS DO PROJETO DE PESQUISA}

Título da Pesquisa: Simulação clínica em comunicação na educação em enfermagem: estudo randomizado sobre a satisfação, confiança e auto percepção de estudantes

Pesquisador: Anaísa Bianchini

Área Temática:

Versão: 2

CAAE: 89840418.1 .0000 .5393

Instituição Proponente: Escola de Enfermagem de Ribeirão Preto - USP

Patrocinador Principal: Financiamento Próprio

\section{DADOS DO PARECER}

Número do Parecer: 2.739.671

Apresentação do Projeto:

Trata-se da avaliação das respostas às pendências.

Objetivo da Pesquisa:

Sem alterações

Avaliação dos Riscos e Benefícios:

Sem alterações

Comentários e Considerações sobre a Pesquisa:

Sem alterações

Considerações sobre os Termos de apresentação obrigatória:

A interessada apresentou a autorização para a coleta de dados na Santa Casa de Sertãozinho, assinada pela Enfa. Coordenadora Assistencial.

Recomendações:

Não há

Conclusões ou Pendências e Lista de Inadequações:

Projeto aprovado

Considerações Finais a critério do CEP:

Parecer aprovado Ad Referendum

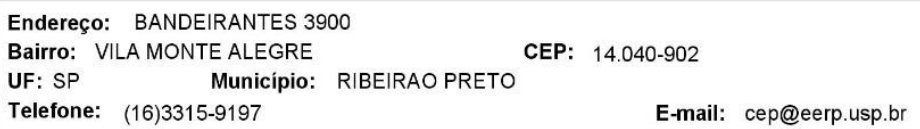




\section{USP - ESCOLA DE \\ ENFERMAGEM DE RIBEIRÃO PRETO DA USP}

Continuaçāo do Parecer: 2.739 .671

Este parecer foi elaborado baseado nos documentos abaixo relacionados:

\begin{tabular}{|c|c|c|c|c|}
\hline Tipo Documento & Arquivo & Postagem & Autor & Situação \\
\hline $\begin{array}{l}\text { Informações Básicas } \\
\text { do Projeto }\end{array}$ & $\begin{array}{l}\text { PB_INFORMAÇÕES_BÁSICAS_DO_P } \\
\text { ROJETO 1132076.pdff }\end{array}$ & $\begin{array}{c}25 / 06 / 2018 \\
01: 08: 19 \\
\end{array}$ & & Aceito \\
\hline $\begin{array}{l}\text { Projeto Detalhado / } \\
\text { Brochura } \\
\text { Investigador }\end{array}$ & $\begin{array}{l}\text { Projeto_Pesquisa_Anaisa_Versao_2_C } \\
\text { EP.pdf }\end{array}$ & $\begin{array}{c}25 / 06 / 2018 \\
01: 07: 01\end{array}$ & Anaísa Bianchini & Aceito \\
\hline $\begin{array}{l}\text { Declaração de } \\
\text { Instituição e } \\
\text { Infraestrutura }\end{array}$ & Autorizacao_Santa_Casa_Anaisa.pdf & $\begin{array}{c}22 / 06 / 2018 \\
13: 03: 58\end{array}$ & Anaísa Bianchini & Aceito \\
\hline $\begin{array}{l}\text { Declaração de } \\
\text { Pesquisadores }\end{array}$ & $\begin{array}{l}\text { Oficio_Encaminhamento_Anaisa_Versa } \\
\text { 0_2.pdf }\end{array}$ & $\begin{array}{c}22 / 06 / 2018 \\
13: 01: 37 \\
\end{array}$ & Anaísa Bianchini & Aceito \\
\hline $\begin{array}{l}\text { Declaração de } \\
\text { Pesquisadores }\end{array}$ & Oficio_Encaminhamento_v2_Anaisa.pdf & $\begin{array}{c}17 / 05 / 2018 \\
15: 07: 03\end{array}$ & Anaísa Bianchini & Aceito \\
\hline $\begin{array}{l}\text { Projeto Detalhado / } \\
\text { Brochura } \\
\text { Investigador }\end{array}$ & $\begin{array}{l}\text { Projeto_de_Pesquisa_Anaisa_Bianchini } \\
\text { _CEP.pdf }\end{array}$ & $\begin{array}{c}14 / 05 / 2018 \\
08: 16: 34\end{array}$ & Anaísa Bianchini & Aceito \\
\hline $\begin{array}{l}\text { Declaração de } \\
\text { Instituição e } \\
\text { Infraestrutura }\end{array}$ & Autorizacao_Instituicao_Anaisa.pdf & $\begin{array}{c}14 / 05 / 2018 \\
08: 13: 42\end{array}$ & Anaísa Bianchini & Aceito \\
\hline $\begin{array}{l}\text { TCLE / Termos de } \\
\text { Assentimento / } \\
\text { Justificativa de } \\
\text { Ausência } \\
\end{array}$ & TCLE_Entrevista_em_estagio.pdf & $\begin{array}{c}14 / 05 / 2018 \\
08: 13: 15\end{array}$ & Anaísa Bianchini & Aceito \\
\hline $\begin{array}{l}\text { TCLE / Termos de } \\
\text { Assentimento / } \\
\text { Justificativa de } \\
\text { Ausência }\end{array}$ & TCLE_simulacao_com_atores.pdf & $\begin{array}{c}14 / 05 / 2018 \\
08: 12: 42\end{array}$ & Anaísa Bianchini & Aceito \\
\hline $\begin{array}{l}\text { TCLE / Termos de } \\
\text { Assentimento / } \\
\text { Justificativa de } \\
\text { Ausência } \\
\end{array}$ & TCLE_capacitacao.pdf & $\begin{array}{c}14 / 05 / 2018 \\
08: 11: 59\end{array}$ & Anaísa Bianchini & Aceito \\
\hline Orçamento & Orcamento_Anaisa.pdf & $\begin{array}{c}14 / 05 / 2018 \\
08: 10: 30\end{array}$ & Anaísa Bianchini & Aceito \\
\hline Cronograma & Cronograma_Anaisa_Bianchini.pdf & $\begin{array}{c}14 / 05 / 2018 \\
08: 08: 39 \\
\end{array}$ & Anaísa Bianchini & Aceito \\
\hline Folha de Rosto & Folha_de_Rosto_Assinada.pdf & $\begin{array}{c}14 / 05 / 2018 \\
08: 07: 59 \\
\end{array}$ & Anaísa Bianchini & Aceito \\
\hline
\end{tabular}

Situação do Parecer:

Aprovado

Necessita Apreciação da CONEP:

Não

Endereço: BANDEIRANTES 3900

Bairro: VILA MONTE ALEGRE

UF: SP Municipio: RIBEIRAOPRETO CEP: 14.040-902

Telefone: (16)3315-9197

E-mail: cep@eerp.usp.br 


\section{USP - ESCOLA DE ENFERMAGEM DE RIBEIRÃO PRETO DA USP}

Continuação do Parecer: 2.739 .671

RIBEIRAO PRETO, 27 de Junho de 2018

Assinado por:

Angelita Maria Stabile

(Coordenador)

Endereço: BANDEIRANTES 3900

Bairro: VILA MONTE ALEGRE

UF: SP Município: RIBEIRAO PRETO

CEP: $14.040-902$

Telefone: (16)3315-9197

E-mail: cep@eerp.usp.br

Página 03 de 03 


\section{ANEXO B - Ferramenta de Avaliação da Comunicação em Saúde (HCAT) ()}

Para cada comportamento listado abaixo, atribua o número que representa sua resposta baseada na seguinte escala:

$$
1=\text { concordo fortemente; } 2 \text { = concordo; } 3 \text { =indeciso; } 4 \text { =discordo; } 5=\text { discordo }
$$

\section{fortemente}

1. O estudante/profissional apresentou-se ao paciente e/ou família

2. O estudante/profissional apertou a mão do paciente e/ou família ou cumprimentou apropriadamente.

3. O estudante/profissional explicou a razão de sua visita em termos apropriados.

4. O estudante/profissional usou comunicação positiva, incluindo um sorriso para encorajar as interações.

5. O estudante/profissional manteve contato visual enquanto conversava com o paciente e/ou família.

6. O estudante/profissional comunicou o que estava prestes a fazer ANTES de fazê-lo.

7. O estudante/profissional perguntou ao paciente ou familiar se poderia tocar o paciente ANTES de fazer um procedimento ou exame (pressão arterial, ausculta, punção venosa, sondagem, etc.)

8. O estudante/profissional tocou o paciente apropriadamente.

9. O estudante/profissional passou a maior parte do tempo perto do paciente.

10. O estudante/profissional sentou-se ao orientar ou conversar com o paciente.

11. O estudante/profissional ouviu mais do que falou.

12. O estudante/profissional inclinou-se em direção à pessoa que falava para demonstrar interesse.

13. O estudante/profissional orientou efetivamente o paciente e/ou família sobre o procedimento, doença, e/ou tratamento.

14. O estudante/profissional fez perguntas para encorajar o feedback e aumentar a clareza.

15. O estudante/profissional reconheceu e respondeu apropriadamente a comportamentos verbais e não-verbais (franzir de testa, lágrimas, histeria, silêncio, etc.) do paciente e/ou família.

16. O estudante/profissional usou tom de voz e volume apropriados para a situação.

17. O estudante/profissional evitou julgar comportamentos do paciente/família (ex. condição econômica, abuso, uso de drogas, orientação sexual, religião/diferenças culturais, etc.).

18. O estudante/profissional passou um tempo igual ou maior abordando aspectos psicossociais no cuidado ao paciente/família em relação aos aspectos clínicos (biológicos). 
19. O estudante/profissional perguntou sobre os sentimentos do paciente/família sobre a situação, demonstrando preocupação.

20. O estudante/profissional reconheceu o conflito e tentou obter informações e encontrar oportunidades para minimizá-lo ou manejá-lo.

21. O estudante/profissional desenvolveu, manteve ou aprimorou relacionamento interpessoal com o paciente e/ou família (via comunicação e profissionalismo)

22. O estudante/profissional evitou termos técnicos de saúde (sinais vitais, punção venosa, etc.) [inclua abaixo os termos técnicos utilizados]

Se termos técnicos foram utilizados, liste-os:

Nome:

Profissão:

Cenário:

Data: 


\section{ANEXO C - Satisfação dos estudantes e autoconfiança na aprendizagem}

Instruções: Este questionário consta de uma série de declarações sobre as suas atitudes pessoais referente à orientação que recebeu durante a atividade de simulação. Cada item representa uma declaração sobre a sua atitude em relação à satisfação com a aprendizagem e a autoconfiança. Não há respostas certas ou erradas. Você vai provavelmente concordar com algumas declarações e não concordar com outras. Por favor, indique o seu sentimento sobre cada afirmação abaixo, marcando os números que melhor descrevem a sua atitude ou crenças. Por favor, seja sincero e descreva sua atitude como ela realmente é, não o que gostaria que fosse. As respostas são anônimas, sendo os resultados compilados em grupo, e não individualmente.

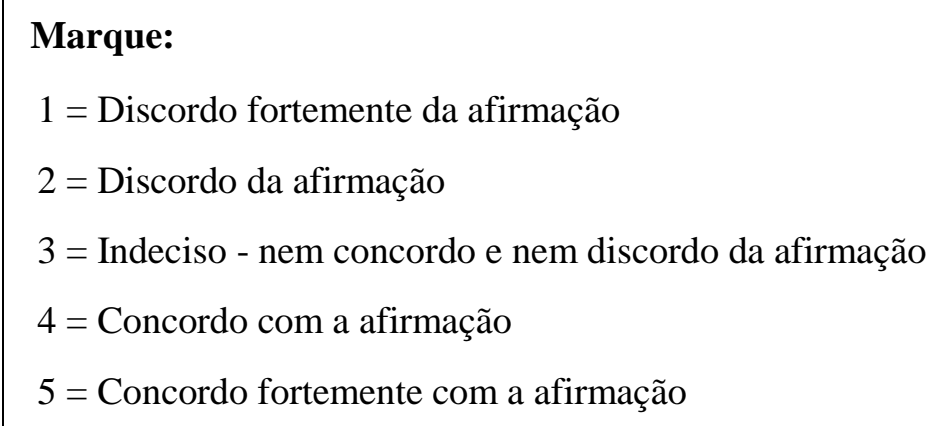

$1=$ Discordo fortemente da afirmação

2 = Discordo da afirmação

3 = Indeciso - nem concordo e nem discordo da afirmação

4 = Concordo com a afirmação

5 = Concordo fortemente com a afirmação

\begin{tabular}{|c|c|c|c|c|c|}
\hline 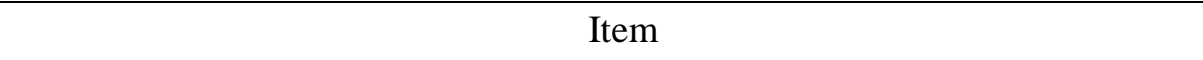 & & & & & \\
\hline Satisfação com a aprendizagem atual & & & & & \\
\hline & DT & D & IN & $\mathrm{C}$ & CT \\
\hline 1. Os métodos de ensino utilizados nesta simulação foram úteis e eficazes. & & & & & \\
\hline & O 1 & $\mathrm{O} 2$ & O 3 & $\mathrm{O} 4$ & O 5 \\
\hline 2. A simulação forneceu-me uma variedade de materiais didáticos e atividades para & & & & & \\
\hline promover a minha aprendizagem do currículo médico-cirúrgico. & O 1 & $\mathrm{O} 2$ & O 3 & $\mathrm{O} 4$ & O 5 \\
\hline 3. Eu gostei do modo como meu professor ensinou através da simulação. & & & & & \\
\hline & $\mathrm{O} 1$ & $\mathrm{O} 2$ & O 3 & $\mathrm{O} 4$ & O 5 \\
\hline 4. Os materiais didáticos utilizados nesta simulação forammotivadorese & & & & & \\
\hline ajudaram-me a aprender. & O 1 & $\mathrm{O} 2$ & O 3 & $\mathrm{O} 4$ & O 5 \\
\hline 5. A forma como o meu professor ensinou através da simulação foi adequada para a & & & & & \\
\hline forma como eu aprendo. & O 1 & $\mathrm{O} 2$ & O 3 & $\mathrm{O} 4$ & O 5 \\
\hline A autoconfiança na aprendizagem & DT & D & IN & $\mathrm{C}$ & CT \\
\hline 6. Estou confiante de que domino o conteúdo da atividade de simulação que meu & & & & & \\
\hline & $\mathrm{O} 1$ & $\mathrm{O} 2$ & O 3 & $\mathrm{O} 4$ & O 5 \\
\hline $\begin{array}{l}\text { 7. Estou confiante que esta simulação incluiu o conteúdo necessário para o domínio do } \\
\text { currículo médico-cirúrgico. }\end{array}$ & & & & & \\
\hline
\end{tabular}




\begin{tabular}{|c|c|c|c|c|c|}
\hline & $\mathrm{O} 1$ & $\mathrm{O} 2$ & O 3 & $\mathrm{O} 4$ & O 5 \\
\hline $\begin{array}{l}\text { 8. Estou confiante de que estou desenvolvendo habilidades e obtendo os } \\
\text { conhecimentos necessários a partir desta simulação para executar os } \\
\text { procedimentos necessários em um ambiente clínico. }\end{array}$ & O 1 & $\mathrm{O} 2$ & O 3 & $\mathrm{O} 4$ & O 5 \\
\hline 9. O meu professor utilizou recursos úteis para ensinar a simulação. & O 1 & O 2 & O 3 & $\mathrm{O} 4$ & O 5 \\
\hline $\begin{array}{l}\text { 10.É minha responsabilidade como o aluno aprender o que eu preciso saber através da } \\
\text { atividade de simulação. }\end{array}$ & O 1 & O 2 & O 3 & O 4 & O 5 \\
\hline $\begin{array}{l}\text { 11.Eu sei como obter ajuda quando eu não entender os conceitos abordados na } \\
\text { simulação. }\end{array}$ & O 1 & $\mathrm{O} 2$ & O 3 & $\mathrm{O} 4$ & O 5 \\
\hline 12. Eu sei como usar atividades de simulação para aprender habilidades. & $\mathrm{O} 1$ & $\mathrm{O} 2$ & O 3 & $\mathrm{O} 4$ & O 5 \\
\hline $\begin{array}{l}\text { 13.Éresponsabilidade do professor dizer-me o que eu preciso aprender na } \\
\text { temática desenvolvida na simulação durante a aula. }\end{array}$ & O 1 & O 2 & O 3 & O 4 & O 5 \\
\hline
\end{tabular}

\section{Autorização para uso da escala de Satisfação dos estudantes e autoconfiança na aprendizagem}

Uso de instrumento Inbox $x$

Anaísa Bianchini <anaisa.bianchini@usp.br>

to rodrigoguimara., Rodrigo

Prezado Dr. Rodrigo Guimarães, bom dia

Venho solicitar por meio deste e-mail, a autorização do uso da

"Escala de Satisfação de Estudantes e Autoconfiança na Aprendizagem"

obtida por meio do estudo "Validação para a lingua portuguesa da escala Student Satisfactionand Self-Confidence in Learning"

para realização de uma pesquisa de nível mestrado do Programa Enfermagem Fundamental da Escola de Enfermagem de Ribeirão Preto.

Neste estudo, tipo experimental, será realizada uma simulação de alta fidelidade com alunos e seria ideal a aplicação da escala para mensı pesquisadores envolvidos.

Aguardo sua resposta,

Att.

Prezada Anaísa,

É com muita satisfação que recebo seu e-mail, a saber do seu interesse na investigação da simulação clínica. Sendo assim por meio deste autorizo a utilização do instrumento solicitado: Escala de Satisfação de Estudantes e Autoconfiança na Aprenc Qualquer dúvida me coloco a disposição para todo e qualquer esclarecimento. 